\title{
Prevalence and Risk of Mild Cognitive Impairment (MCI) in Low and Middle-Income Countries: A
}

\section{Systematic Review}

Andrea M McGrattan ${ }^{1 *}$, Yueping Zhu², Connor D Richardson ${ }^{1}$, Devi Mohan ${ }^{3,4}$, Yee Chang Soh ${ }^{3,4}$, Ayesha Sajjad $^{5}$, Carla van Aller ${ }^{1}$, Shulin Chen $^{2}$, Stella-Maria Paddick ${ }^{6,7}$, Matthew Prina ${ }^{8}$, Mario Siervo ${ }^{9}$, Louise A Robinson $^{1}$ and Blossom CM Stephan ${ }^{10}$

${ }^{1}$ Population Health Sciences Institute, Newcastle University, UK

${ }^{2}$ Department of Psychology and Behavioral Science, Zhejiang University, Hangzhou, China

${ }^{3}$ Global Public Health. Jeffrey Cheah School of Medicine and Health Sciences, Monash University Malaysia, Selangor, Malaysia.

${ }^{4}$ South East Asia Community Observatory (SEACO), Monash University Malaysia, Segamat, Malaysia

${ }^{5}$ Department of Epidemiology Erasmus MC University Medical Center Rotterdam Rotterdam The Netherlands.

${ }^{6}$ Translational and Clinical Research Institute, Newcastle University, UK

${ }^{7}$ Gateshead NHS Community Health Foundation Trust

${ }^{8}$ Social Epidemiology Research Group, Health Service and Population Research Department, King’s College London, London, UK

${ }^{9}$ School of Life Sciences, The University of Nottingham Medical School, Nottingham, United Kingdom.

${ }^{10}$ Institute of Mental Health, Division of Psychiatry and Applied Psychology, Nottingham University, UK.

\section{*Corresponding author}

Dr Andrea McGrattan

Population Health Sciences Institute

Newcastle University

Biomedical Research Building

Campus for Ageing and Vitality

Newcastle upon Tyne

NE4 5PL

Tel: +44 (0) 1912085467

Email: andrea.mcgrattan@newcastle.ac.uk

\section{Target Journal JAD}

Word count (main body text): 4589 


\section{ABSTRACT}

Introduction Mild Cognitive Impairment (MCI) is a cognitive state associated with increased risk of dementia. Little research on MCI exists from low-and middle-income countries (LMICs), despite high prevalence of dementia in these settings.

Objective This systematic review aimed to review epidemiological reports to determine the prevalence of MCI and its associated risk factors in LMICs.

Methods Medline, Embase and PsycINFO were searched from inception until November 2019. Eligible articles reported on MCI in population or community-based studies from LMICs. No restrictions on the definition of MCI used as long as it was clearly defined.

Results 4,621 articles were screened, and 78 retained. In total, n=23 different LMICs were represented; mostly from China ( $\mathrm{n}=55$ studies). Few studies from countries defined as lower-middle income ( $\mathrm{n}=14)$, low income $(n=4)$, or from population representative samples $(n=4)$. There was large heterogeneity in how MCI was diagnosed; with Petersen criteria the most commonly applied $(n=26)$. Prevalence of aMCI (Petersen criteria) ranged from $0.6 \%$ to $22.3 \%$. Similar variability existed across studies using the International Working Group Criteria for aMCI (range 4.5\% to 18.3\%) and all-MCI (range 6.1\% to 30.4\%). Risk of MCI was associated with demographic (e.g. age), health (e.g. cardio-metabolic disease) and lifestyle (e.g. social isolation, smoking, diet and physical activity) factors.

Conclusion Outside of China, few MCI studies have been conducted in LMIC settings. There is an urgent need for population representative epidemiological studies to determine MCI prevalence in LMICs. MCI diagnostic methodology also needs to be standardised. This will allow for cross-study comparison and future resource planning.

Key words: Epidemiology, Low-and Middle-Income Country (LMIC), Mild Cognitive Impairment (MCI), Prevalence, Risk Factors, Systematic Review 


\section{INTRODUCTION}

Mild Cognitive Impairment (MCI) defines an intermediate state of cognitive function between normal ageing and dementia. Numerous definitions for MCI exist and prevalence estimates vary (range $<1 \%$ up to $56 \%$ across different studies and definitions) depending on population sampling (age, clinical $v s$ population), MCI case definition and operationalisation of the component criterion for an MCI case diagnosis [1-7]. However, the majority of MCI research has been undertaken in high-income countries, namely North America, Europe and Australia. This raising questions of generalisability of findings to low-and middle-income countries (LMIC) which vary by wealth, culture, ethnicity, research capacity and infrastructure to support ageing populations.

Studies examining MCI prevalence in LMICs have produced conflicting results. For example, the 10/66 study reported a range of estimates (0.8 to 4.3\%) of Petersen defined amnestic MCI (aMCI) [8] across sites in Cuba, the Dominican Republic, Peru, Venezuela, Mexico, China, India and Puerto Rico [9]. Findings from the World Health Organization's Study on Global Ageing and Adult Health reported an overall MCI prevalence of 15.3\% (95\%CI: 14.4-16.3) when applying the National Institute of AgeingAlzheimer's Association (NIA-AA) criteria [10] across sites in China, Ghana, India, Mexico Russia, and South-Africa [11]; with the individual country prevalence estimates lower (e.g. 8.5\% in South Africa [12]). It is not clear what is driving the differences. Within studies, the differences likely reflect variability in the profile of risk and protective factors across sites as well as cultural/ethnic perceptions of cognitive ageing and symptom reporting. Across studies, differences are likely due to heterogeneity in methodology e.g. differences in sample selection and the MCI criteria used for diagnosis.

While some have suggested that MCI as a mode of prodromal classification can have a limited role in clinical and epidemiological settings, others argue that MCI could be a pragmatic tool for identifying individuals who could benefit from risk reduction [13]. There is promising evidence to support dementia risk reduction interventions in HICs [14], with indications of similar opportunities in LMICs [15]. Determining how best to identify individuals with MCI and the prevalence of the condition in LMICs will have important implications for planning intervention trials, treatment strategies, budgeting and 
public health surveillance. While several reviews on MCI have been conducted [1-7], to our knowledge none have focused specifically on LMIC settings. Therefore, the aim of this systematic review was to report on the population prevalence and risk factors for MCI in these settings. No restrictions were applied to the definition of MCI used as long as it was clearly defined.

\section{MATERIALS AND METHODS}

This review adhered to standard reporting guidelines [16] and full details of the MOOSE checklist [17] are in Appendix I. The review protocol can be made available by a member of the research team upon request.

\section{Search Strategy}

Medline, Embase and PsycINFO were searched from inception to the 10 January 2018, with updated searches run from 10 January 2018-6 November 2018 and from 6 November 2018-30 November 2019 (CR; See Supplementary Table 1 for the list of search terms).

\section{Inclusion/Exclusion Criteria}

Studies were included if: (1) the sample was from a LMIC, at the time of the study, as defined by The World Bank[18]; (2) the study reported population-level or community-based data; and, both crosssectional and cohort study designs were included; (3) the study described how MCI had been mapped; (4) sample age was $\geq 50$ years; and, (5) MCI prevalence was reported. No restrictions were placed on the definition of MCI used, language or publication date. Randomised controlled trials, case-control studies, unpublished studies, and conference abstracts were excluded. Studies were also excluded if, for analysis, cognitive groups (e.g. dementia and MCI groups) were combined or the sample restricted (e.g. studies investigating MCI in disease specific groups such as diabetics or in illiterate participants only). Reviews were also retained and the reference lists of these interrogated for any missed paper.

\section{Data Analysis}


Titles/abstracts were first screened, followed by the full text of any identified articles (CR and CVA). Where multiple publications using the same study were identified, these were retained for full text review and kept if they presented original findings. Disagreements were resolved by consensus or a third party (BCMS). Data including study characteristics, operationalisation of MCI criteria, and MCI prevalence estimates were independently extracted by four investigators (AMG [Chinese Studies], AS, BCMS and CVA).

Study quality (bias) was assessed using the tool developed by Hoy et al [19]. Nine items were selected related to representativeness of the study sample, methods for case definition, and the statistical calculation of MCI prevalence. Each risk of bias item was scored '0' (low risk) or ' 1 ' (high risk) of bias (total score range: 0 to 9).

Forest plots of the population prevalence estimates of MCI, defined using the most commonly applied criteria across the studies were created Prism-GraphPad 8 for Windows (GraphPad Software, San Diego, USA). This included plots for MCI defined using Petersen criteria (including all-MCI and aMCI; n=26 studies [9, 20-44]), International Working Group (IWG) criteria (n=14 studies [45-58]), or study specific criteria for Cognitive Impairment no Dementia (CIND; n=10 studies [59-68]). A meta-analysis was not possible due to large heterogeneity in methodology across the studies and the lack of key statistical information (i.e. confidence intervals for the MCI prevalence estimates) in most studies.

\section{Role of the funding source}

The review was completed as part of the NIHR Global Health Group: DePEC (Grant number: 16/137/62). AMG and BCMS have full access to the data and final responsibility to submit for publication.

\section{RESULTS}

\section{Search Yields}


The electronic search identified n=4,548 studies, with duplicates removed (See Figure 1). Following title/abstract screening, 162 studies were selected for full text review. This included a systemic review on MCI prevalence in China [7], where an additional n=48 studies in Mandarin were identified. These were added to the review giving a total of $n=210$ full text studies. From these, 73 studies were selected for inclusion. An updated electronic search in November 2019 yielded 972 studies, and an additional five were included (total $n=78$ studies). Two studies $[66,67]$ used the same dataset, but these were retained as they provided MCI prevalence estimates for different age groups.

\section{Study Characteristics}

Table 1 shows the characteristics of each study. Sample size ranged from $n=120$ [69] to $n=32,715$ [11]. Most studies included participants aged $\geq 60$ years ( $\mathrm{n}=46$ studies [22, 25-30, 32, 35-42, 47, 52-56, 58, $60,61,65,67,68,70-87])$ or $\geq 65$ years ( $\mathrm{n}=16$ studies $[9,23,33,44,46,48,50,51,57,62-64,69,88-$ 90]). The remaining studies included participants aged $\geq 50$ years ( $n=6$ studies $[11,21,59,91-93]), \geq 55$ years ( $n=7$ studies [24, 31, 34, 43, 94-96]), $\geq 70$ years ( $n=1$ study [49]), and $\geq 80$ years ( $n=2$ studies [20, 66]). One study [92] included only women.

As shown in Table 1 , four studies $[9,11,50,64]$ analysed MCI prevalence for multiple countries. The majority of studies have been conducted in China ( $\mathrm{n}=55$ studies $[9,11,20,24,26-45,48,51,52,54$, 56-58, 62, 66-68, 72-84, 86, 87, 89, 90, 94-96]), followed by India (n=6 studies [9, 11, 25, 85, 91, 92]), Mexico ( $n=4$ studies [9, 11, 22, 65]), Brazil ( $n=2$ studies [59, 60]), Malaysia ( $n=2$ studies [47, 53]), the Philippines ( $\mathrm{n}=2$ studies [61, 69]), Central African Republic ( $\mathrm{n}=2$ studies [50, 64]), South Africa ( $\mathrm{n}=2$ studies [11, 93]), Republic of Congo ( $\mathrm{n}=2$ studies [50, 64]), and one each in Colombia [21], Nigeria [23], Cuba [9], Dominican Republic [9], Peru [9], Venezuela [9], Georgia [46], Kazakhstan [55], Tanzania [49], Bulgaria [88], Ghana [11], Russia [11], Egypt [70] and Benin West-Africa [63]. Therefore, most studies ( $\mathrm{n}=67$ studies [9, 11, 20-22, 24, 26-45, 47, 48, 51-60, 62, 65-68, 71-84, 86-90, 94-96]) were from sites in upper middle-income countries, 14 studies [9, 11, 23, 25, 46, 50, 55, 61, 64, 70, 85, 91-93] were from sites in lower middle-income countries, and four studies [49, 50, 63, 64] were from sites in low-income countries. One study [9] included data collected during 2003-2007 from eight 
sites, one of which was Puerto Rico. This country was declared high-income by the World Bank in 2002. Therefore, the prevalence data for Puerto Rico has been excluded. Only four studies [11, 44, 65, 93] selected participants from a representative country-wide sample. The remaining studies included a sample of community residents from a specific region, city or district(s).

\section{Quality Assessment}

The detailed quality assessment is reported in Table 2 of the supplementary material. Two studies [44, 93] obtained a low risk of bias score across all nine domains assessed, with the majority of studies ( $\mathrm{n}=66$ studies) only having high risk scores in 1-3 domains [9, 11, 21-43, 46, 48-51, 53-57, 60, 61, 63, 65-68, 70-73, 75-78, 80-86, 88-91, 94-96]. These were mostly related to a lack of, or unclear use of, randomisation procedures and that the study sample was unlikely to be representative of the national population.

\section{Criteria}

A shown in Table 1, numerous criteria were used to diagnose MCI including (1) Petersen's criteria [8, 97-102] ( $\mathrm{n}=26$ studies [9, 20-44]); (2) IWG criteria[103] (n=14 studies [45-58]); (3) study specific criteria for CIND ( $\mathrm{n}=10$ studies [59-68]); (4) study specific criteria for MCI ( $\mathrm{n}=13$ studies [30, 70, 7476, 79, 80, 84, 86, 89, 91, 94, 95]); (5) DSM-IV criteria [104] (n=8 studies [72, 77, 78, 81-83, 90, 96]); (6) MCI based on a score from a neuropsychological assessment tool ( $\mathrm{n}=3$ studies [69, 87, 92]); (7) NIA-AA criteria [10] (n=2 studies [11, 93]); or, (8) the European Consortium on Alzheimer's Disease (ECAD) criteria [105] (n=2 studies [85, 88]). A full description of the different MCI criteria applied across the studies is in Supplementary Tables 3 and 4.

\section{Operationalising MCI criteria}

Full details of how MCI criteria were operationalised (and any modifications that were made to mapping the original diagnostic criteria) are detailed below and outlined in Supplementary Table 5. Overall, MCI was diagnosed using one or more of the following criteria (1) subjective/informant cognitive or memory complaint; (2) global cognitive performance; (3) domain specific cognitive performance; (4) physical 
functioning; (5) no dementia; and, (6) other factors (e.g. disease related co-mobility). Additional assessments were used in 7/78 studies [24, 27, 45, 47, 51, 62, 70]. In four studies a Clinical Dementia Rating (CDR) score between 0 and 0.5 [27], or a score of 0.5 was needed for diagnosis of MCI [24, 45, 51]. In four studies [24, 47, 62, 70] it was required that cognitive impairment was independent of other factors such as depression.

\section{Domain Specific MCI}

Based on the cognitive domain test scores, 17 studies [9, 20-24, 26, 43, 45-48, 51-53, 70, 91] stratified MCI into different subtypes. This included non-amnestic MCI (naMCI; n=8 studies [22, 23, 43, 45-48, 51]), aMCI single domain (aMCI-SD; $\mathrm{n}=4$ studies [22, 23, 43, 48]), multi-domain aMCI (aMCI-MD) ( $\mathrm{n}=5$ studies [22, 23, 43, 46, 48]), multi-domain non-amnestic MCI (naMCI-MD; n=4 studies) [22, 23, 46, 48], and single domain naMCI (naMCI-SD; $\mathrm{n}=3$ studies [22, 23, 48]).

\section{Subjective Cognitive/Memory Complaint}

Cognitive/memory complaints were included as part of the MCI diagnosis in 57/78 studies [9, 11, 2024, 26-29, 31-34, 36-43, 45, 47-56, 58-60, 62, 70, 72-76, 78-83, 85, 88, 90, 91, 93-95]. Complaint was typically required to be subjective and focused on memory ( $\mathrm{n}=43$ studies $[9,11,20-22,24,26-28,31-$ 34, 36-43, 47, 48, 52, 53, 58-60, 62, 70, 72-74, 76, 78, 79, 81-83, 90, 95]) or cognition in general (n=11 studies [23, 45, 49-51, 54, 56, 75, 80, 85, 88]). In 25 studies, complaints could also be reported by an informant [22, 23, 27, 28, 44, 45, 47, 48, 51, 52, 54-56, 60, 62, 70, 72, 73, 75, 76, 80, 85, 91, 94, 95]. Thirty studies did not specify how cognitive/memory complaints were assessed or the information was not reported [20, 24-26, 29, 30, 43, 44, 46, 49, 50, 55, 57, 61, 63-69, 77, 84, 87-89, 92, 93, 96].

\section{Global Cognitive Function}

Global cognitive function was assessed in 61/78 studies [21-23, 25-34, 36-44, 46, 47, 50, 52-54, 57-70, 72-76, 78-83, 88-92, 95, 96]. In 33 studies [23, 25, 29, 32, 39-41, 50, 57-70, 74, 75, 79-83, 88, 90, 92, 95], global cognitive function was required to be impaired, while in 28 studies [21, 22, 26-28, 30, 31, $33,34,36-38,42-44,46,47,52-54,72,73,76,78,89,91,94,96]$ it was required to be preserved or 
within normal limits. In total, 10 different neuropsychological assessment tools were used to assess global cognitive function including the Mini Mental State Examination (MMSE; n=40 studies[20, 22, $25-27,30,31,33,34,36,43,47,52-54,57,59,60,62,66-69,72,74-76,78,80-83,88-92,95,96])$, the Montreal Cognitive Assessment (MoCA; $n=10$ studies [27, 29, 32, 39-41, 46, 58, 79, 89]), the Clinical Dementia Rating scale (CDR; $n=5$ studies [44, 61, 66, 67, 70]), the Community Screening Instrument for Dementia (CSI-D; n=3 studies [50, 63, 64]), the Consortium to Establish a Registry for Alzheimer's Disease battery (CERAD; $n=2$ studies [21, 91]), the Five Word Test (FWT; $n=2$ studies [63, 64]), the Cambridge Examination for Mental Disorders-Revised (CAMDEX-R; $n=1$ study [20]), the Identification and Intervention for Dementia in Elderly Africans (IDEA) cognitive screen ( $\mathrm{n}=1$ study[23]), The Memory Impairment Screen (MIS; $n=1$ study [88]), and the Informant Questionnaire on Cognitive Decline in the Elderly (IQCODE; n=1 study [65]). Of the studies using the MMSE, and with reported cut-off scores, 22 studies [26, 27, 30, 31, 33, 57, 59, 60, 62, 67, 72, 73, 75, 80-83, 89, 90, 94-96] used education specific cut-off scores, and 16 studies used a mixture of the following:

1. To demonstrate normal cognitive function: MMSE $\geq 24$ ( $n=4$ studies [43, 54, 76, 78]), MMSE one standard deviation (1SD) from norm ( $\mathrm{n}=1$ study [68]), MMSE $\geq 19$ ( $\mathrm{n}=2$ studies [47, 53]), MMSE $\geq 23$ ( $n=1$ study [22]) and MMSE range 24-26 ( $\mathrm{n}=1$ study [36]); and,

2. To demonstrate cognitive impairment: $\operatorname{MMSE} \leq 24$ ( $\mathrm{n}=2$ studies [25, 92]), MMSE $\leq 26(\mathrm{n}=2$ studies [34, 74]), MMSE $\leq 25$ ( $n=1$ study [88]), MMSE $\leq 27$ ( $n=1$ study [66]), and MMSE range 20-25 (n=1 study [69]).

\section{Domain Specific Cognitive Function: Memory}

Memory was individually assessed for impairment in 41 studies [9, 11, 20-24, 26-29, 37-53, 55, 56, 59, $60,62,65,70,73,78,88,90,91,93]$. Some studies used neuropsychological assessment tools to assess memory impairment. The MMSE ( $\mathrm{n}=3$ studies [20, 26, 52]), and the Wechsler Memory Scale (WMS; $\mathrm{n}=3$ studies [27, 48, 62]) were the most frequently used, followed by the MIS ( $\mathrm{n}=2$ studies [22, 88]), the CSI-D ( $n=1$ study [9]), the Cross-Cultural Cognitive Examination (CCCE; $n=1$ study [65]), and the Cambridge Mental Disorders of the Elderly Examination (CAMDEX) ( $\mathrm{n}=1$ study [20]). The remaining studies used individual memory tests, of which the Auditory-Verbal Learning Test (AVLT; $\mathrm{n}=6$ studies 
[43-45, 51, 53, 62]) was most often used followed by the CERAD 10 word learning test ( $\mathrm{n}=5$ studies [9, 11, 21, 49, 93]), the digit span test ( $\mathrm{n}=4$ studies [11, 12, 47, 53]), the Brief Cognitive Screening Battery (BCSB) delayed recall task ( $\mathrm{n}=2$ studies [59, 60]), the Fuld Object Memory Evaluation (FOME; $\mathrm{n}=1$ study [45]), the stick test ( $\mathrm{n}=1$ study [45]), the Renminbi test ( $\mathrm{n}=1$ study [45]), the IDEA 10 word learning test ( $\mathrm{n}=1$ study [23]), the MoCA free delayed recall test ( $\mathrm{n}=1$ study [46]), the Rey-Osterrieth complex figure test ( $\mathrm{n}=1$ study [43]), RAVLT total learning ( $\mathrm{n}=1$ study [47]), RAVLT delayed recall ( $\mathrm{n}=1$ study[47]), the MMSE memory subtask ( $\mathrm{n}=1$ study [48]),WMS-III local memory test ( $\mathrm{n}=1$ study [70]), CDR memory score ( $\mathrm{n}=1$ study [70]), CCCE verbal memory ( $\mathrm{n}=1$ study [65]), and the free and cued selective reminding test ( $\mathrm{n}=1$ study [50]). Eighteen studies describe cut-off scores for impairment including: $<1.5$ SDs adjusted for age and education ( $\mathrm{n}=8$ studies [9, 21, 22, 43, 45, 48, 51, 78]), <1.5 SDs below norms ( $\mathrm{n}=6$ studies [27, 44, 46, 53, 62, 91]), <1 SD below norms ( $\mathrm{n}=2$ studies [47, 70]), <1 SD adjusted for age, education and country ( $\mathrm{n}=2$ studies [11, 93]), and, 1.5-2 SDs below the overall mean adjusted for age and education ( $n=1$ study [56]).

\section{Domain Specific Cognitive Function: Other Domains}

Non-memory cognitive test performance was assessed in 26 studies [11, 22, 23, 25, 27, 43-51, 55, 56, 59, 60, 62, 65, 79, 85, 88, 91, 93]. Eight different test batteries were used including: the Wechsler Adult Intelligence Scale (WAIS; $n=3$ studies [27, 48, 62]), CERAD ( $n=1$ study [88]), CSI-D ( $n=1$ study [49]), the Alzheimer's Disease Assessment Scale Cognitive Subscale (ADAS-COG; n=1 study [22]), IDEA cognitive screen ( $n=1$ study [23]), CAMCOG ( $n=1$ study [25]), MOCA ( $n=1$ study [46]), Malayalam version of Addenbrooke's Cognitive examination (m-ACE; n=1 study [85]), and the CCCE ( $\mathrm{n}=1$ study [65]). In addition, domain-specific tests (e.g. attention and executive function) were used, with the four most common being the verbal fluency test ( $\mathrm{n}=10$ studies [11, 43, 44, 50, 51, 59, 60, 62, 91, 93]), the Trail Making Test (TMT; $n=7$ studies [27, 43-46, 51, 62]), the Clock Drawing Test (CDT; $n=5$ studies [43, 44, 46, 47, 51]), and the Boston Naming Test ( $\mathrm{n}=2$ studies [43, 62]). Two studies [56, 79] stated that non-memory domains were assessed, however they did not describe which tests were used.

\section{Dementia}


Criteria used to exclude dementia included the DSM-IV ( $\mathrm{n}=27$ studies [20, 23, 25, 27, 34, 37, 44-46, 48-51, 55, 59, 61-64, 66-68, 70, 85, 88, 91, 92]), performance on a neuropsychological assessment battery ( $\mathrm{n}=8$ studies [22, 43, 47, 52, 56, 69, 87, 89]), a combination of cognitive test performance and evaluation of Activities of Daily Living (ADL)/ Instrumental Activities of Daily Living (IADL; $n=4$ studies [11, 21, 65, 93]), NINCDS-ADRDA criteria ( $\mathrm{n}=3$ studies [23, 37, 62]), ICD-10 criteria ( $\mathrm{n}=1$ study [25]), the 10/66 dementia algorithm ( $n=1$ study [9]), diagnoses by a doctor ( $n=1$ study [53]) or NIA-AA criteria ( $\mathrm{n}=1$ study [60]).

\section{Functional Performance}

Fifty-six studies reported that physical functioning, including ADL/IADL, were part of the assessment for MCI [9, 11, 20-28, 31-33, 36-38, 42-56, 59, 60, 62, 65-67, 72-76, 79-83, 85, 88, 90, 91, 93-95]. However, 26 of these studies did not report the method used to determine physical functioning status [24-26, 28, 32, 34, 36-38, 42, 43, 46, 48, 49, 56, 72, 73, 75, 76, 79-83, 94, 95]. Thirty-six studies [9, 11, 20, 21, 24-27, 31-33, 37, 38, 42, 45-50, 52-54, 62, 65-67, 73, 74, 88, 90, 95] exclusively assessed either ADL or IADL. The majority of studies required persevered ADL/IADL for a diagnosis of MCI, with only 13 studies [9, 11, 22, 41, 46, 53, 72, 75, 80-83, 91] allowing for subtle changes/mild functional impairment. In 26 studies, impairment in ADL/IADL was assessed using previous developed tools, of which the Katz ADL scale was the most often used ( $\mathrm{n}=8$ studies [11, 20, 22, 27, 47, 52, 53, 93]), followed by the Lawton and Brody scale ( $\mathrm{n}=5$ studies [21, 45, 47, 52, 53]), the Functional Activities Questionnaire (FAQ; $n=4$ studies [44, 51, 55, 60]), the CDR ( $\mathrm{n}=2$ studies [45, 51]), the CSI-D informant interview ( $\mathrm{n}=2$ studies [9, 50]), the Everyday Ability Scale for India ( $\mathrm{n}=2$ studies [85, 91]), the Barthel scale ( $\mathrm{n}=1$ study[21]), the Clinician Home Based Interview to assess Function (CHIF test; $\mathrm{n}=1$ study [23]), and the IQCODE ( $\mathrm{n}=1$ study) [60].

\section{MCI prevalence}

The prevalence estimates reported in this review were all determined at the time of the study. However, one study [86] reported MCI prevalence at two time points (2010 and 2015). Across the different definitions used, 31 studies [11, 22, 23, 25, 27, 30, 31, 43-51, 55, 57, 69, 71, 75, 80, 84-89, 91, 93, 96] 
calculated overall MCI prevalence, 47 studies [9, 20-24, 26, 28, 29, 32, 34-43, 45-48, 51-53, 56, 58, 70, 72-74, 76, 78, 79, 81-83, 90, 91, 94, 95] calculated aMCI prevalence, eight studies [22, 23, 43, 45-48, 51] calculated naMCI prevalence and 10 studies [59-68] calculated CIND prevalence. Two studies [44, 86] subtyped MCI by aetiology as defined by: MCI caused by prodromal Alzheimer's disease [44], MCI resulting from cerebrovascular disease [44], MCI with vascular risk factors[44], MCI with significant memory impairment [86], MCI with significant executive function impairment and relationship with cerebral vascular disease [86] and MCI caused by other factors [86]. As shown in Table 1, MCI prevalence ranged from $0.3 \%$ (95\% CI: $0.1-0.5)$ in a sample from Mexico ( $\mathrm{n}=2,944 ; \geq 60$ years; naMCI multiple domain, Petersen criteria) [22] to 63.3\% in a sample from the Philippines ( $n=120$; $\geq 65$ years; MCI defined as an MMSE score 20-25 out of 30) [69]. Specifically, for Petersen criteria, prevalence of aMCI ranged from 0.6\% (95\%CI: 0.3-0.9) [9] to 22.3\% [26]. Similar variability was seen across studies using the IWG Criteria for aMCI (range 4.5\% [48] to 18.3\% [58]; $\mathrm{n}=9$ studies); IWG criteria for all-MCI (range 6.1\% [50] to 30.4\% [55]; $\mathrm{n}=10$ studies); studies using CIND criteria (range $6.1 \%$ [59] to $47.4 \%$ [66]; $n=10$ studies), studies using study specific criteria to diagnose MCI (range 1.6\% [86] to 27.7\% [80]; $\mathrm{n}=13$ studies); DSM-IV criteria (range 9.8\% [83] to 33.0\% [77]; $\mathrm{n}=8$ studies); studies using neuropsychological tests (range 9.7\% [87] to 63.3\% [69]; n=3 studies); NIA-AA criteria (range 8.5\% [93] to 15.3\% [106]; n=2 studies) and European Consortium of AD criteria (range $6.7 \%$ [88] to $26.1 \%$ [85]; $\mathrm{n}=2$ studies).

The forest plots in Figure 2 show the MCI prevalence estimates for Petersen defined all-MCI (Figure 2A) and aMCI (Figure 2B), the IWG criteria (Figure 2C) and criteria for CIND (Figure 2D). The plots show there is large variability in MCI prevalence across studies even when the same criteria are applied in the same country albeit in different samples. In contrast, prevalence estimates are generally, although not always, more consistent across countries in multi-site studies ( $\mathrm{n}=4$ studies $[9,11,50,64]$ ) when the same methods are used (0.6\%-4.6\% [9]; 6.1\%-7.2\% [50];18.8\%-25.0\% [64]).

\section{Associated Risk Factors}


Risk factors for prevalent MCI were investigated in 64/78 studies [20-24, 26-45, 47, 48, 51-60, 62, 6769, 72-76, 78-87, 89-93, 95, 96]. Two studies [53, 67] did not report risk factor information in the original article, however, risk factor data for the same cohort were later published in a separate article $[107,108]$. In this scenario, we have added the risk factor information as documented in the most recent publication. One paper [27] reported additional vascular risk factor information in a separate article [109] and we have also included this data. Significant risk factors for MCI included increased age ( $\mathrm{n}=46 / 64$ studies [22, 23, 26-42, 44, 45, 48, 51, 54-58, 62, 67, 72-76, 78-82, 84, 89, 90, 92, 94, 96]), sex (n=41/64 studies; in 37 studies [22-24, 26, 28-30, 33, 34, 36, 38-42, 45, 48, 51, 54, 58, 62, 67-69, 72, 73, 76, 78, 81, 84, 86, 89, 90, 93-96] women had higher risk and in four studies [21, 27, 44, 87] men had higher risk), and low level of education ( $\mathrm{n}=44 / 64$ studies [20-23, 27-37, 39-45, 48, 51, 54-57, 62, 67, 72-76, 78-82, 84, 89, 90, 94]). Other significant risk factors included the presence of disease related co-morbidities (e.g. hypertension, stroke, coronary heart disease) [12, 20, 22, 34, 41-44, 48, 56, 60, 67, 84, 86, 89-91, 94], low monthly income/low economic status [27-29, 33, 36, 39-42, 62, 79, 90, 92], marital status (without spouse) [28, 33, 34, 41, 54, 62, 68, 75, 76, 78, 80, 84, 87, 90, 92], occupation (physical labour) [27, 28, 34, 37, 41, 44, 58, 74-76, 78, 81, 83], geographic area (rural location) [37, 51, 68], diabetes [34, 41-44, 48, 84, 86, 90, 91], alcohol consumption [20, 39, 72, 81, 85, 93, 94], high body mass index [22, 48, 86, 89, 94], living alone [28, 29, 32, 34, 36, 38, 72, 78, 79, 81], APOE E4 carrier [32, 94], low physical activity [28, 38, 39, 41, 54, 84], current or a history of smoking [26, 34, 39, 48, 72, 75, 84, 90, 91], sleep (poor) [26, 28, 38, 84], depression [22, 41, 90], and an introverted personality $[29,40,58]$. Protective factors included maintaining social contact with others $[29,43,58,76,78]$ and following a healthy diet/consuming healthy dietary components [35, 40, 43, 81] or specifically drinking tea [26, 35, 43, 89]. See supplementary Table 6 for full details of all risk factors reported across the different studies.

\section{DISCUSSION}

This is the first systematic review, to our knowledge, focused on MCI prevalence and its risk factors specifically in LMICs. The results highlight that MCI research in LMICs is largely restricted to uppermiddle income countries, namely China. Further, MCI research is characterised by wide variation in 
population sampling, the case definition used for an MCI diagnosis, operationalisation of the component criterion and prevalence estimates. These differences make cross-study comparison extremely difficult and highlight the urgent need for consensus in how MCI is defined across different settings.

MCI prevalence ranged from $0.3 \%$ [22] to $63.3 \%$ [69]. This variability was not reduced when grouping prevalence estimates by case definition. However, as shown in Figure 2, there was a general pattern. Similar to what is observed in high income countries [110] we found that diagnostic criteria that are more restrictive and capture a single impairment (e.g. Petersen aMCI criteria; range $0.6 \%$ (95\%CI: 0.30.9) [9] to 22.3\% [26]) have generally lower prevalence estimates compared to more general criteria that capture broader dysfunction (e.g. CIND where the majority of studies $n=7 / 10$ reported a prevalence $>15 \%)$. Although it is important to note that estimated prevalence for specific criteria did vary considerably. In relation to age, across all definitions, MCI appears to be rare in the very young, i.e. people $<50$ years. Furthermore, aMCI (Petersen Criteria) and IWG generally have a lower prevalence in studies where people are aged $\geq 65$ vs people aged $\geq 60$ with the opposite trend observed for all MCI (Petersen Criteria) and CIND.

Regarding definition, across studies, the most widely applied criteria were Petersen defined aMCI (n=26 studies [9, 20-44]) requiring subjective/informant memory complaint, normal global cognitive function, impaired memory, preserved (or relatively preserved in later definitions) physical function and no dementia. Prevalence of aMCI ranged from 0.6\% (95\%CI: 0.3-0.9) [9] to 22.3\% [26]. Similar variability was seen across studies using the IWG Criteria for aMCI (range 4.5\% [48] to 18.3\% [58]) and IWG criteria for all-MCI (range 30.4\% [55] to 6.1\% [50]). These results are in line with previous systematic reviews of MCI incorporating studies predominately from high-income countries [111]. Variability in prevalence is likely due to differences in sample characteristics (e.g. age, educational attainment and distribution of risk and protective factors) and methodology (e.g. test batteries used to assess cognitive and physical function, cut-off scores for impairment and whether the analyses were adjusted for factors such as age, sex and education) across studies. Indeed, of the studies that included multiple sites all 
demonstrated that when the same methods were used to diagnose MCI, prevalence estimates were generally (although not always) more comparable across countries [9, 11, 50, 64].

Similar to findings in high-income countries, both modifiable and non-modifiable risks factors were identified for MCI. Key socio-demographic risk factors included increased age, sex (usually, but not always female) and low educational attainment. Modifiable health and lifestyle risk factors included, but were not limited to, smoking, presence of cardiovascular related diseases, social contact, occupation, physical activity and dietary related factors. These findings support the development of novel public health interventions to reduce risk of cognitive impairment targeting education, cardio-metabolic health and lifestyle factors that are applicable to the specific context of LMIC settings. However, a key knowledge gap highlighted by the review is the lack of research into context specific risk factors. Indeed, compared to high-income countries factors such as lifelong disadvantage, food insecurity, poverty, and absence of robust health and social care services might also be important in increasing risk of MCI and dementia in these settings.

Of note, is the scarcity of studies on MCI from countries classified as low-income (only $n=4$ studies [49, 50, 63, 64]). Further, no studies were identified from LMICs in the Middle East, with the exception of one study from Egypt [70]. As shown in Figure 3, most MCI research in LMICs has come from cohorts in the Far East (e.g. China and parts of Asia and South-Asia including Malaysia, Philippines and India), South America and the Caribbean (including Cuba, Dominican Republic, Mexico) and an increase in research in Africa (Tanzania, Nigeria, Central African Republic, Republic of Congo) only in the last five years (i.e. from 2015 onwards). Few studies have also been conducted in European LMICs with the exception of Bulgaria [88], Russia [106] and Georgia [46]. This lack of research into MCI could reflect the more recent demographic transition and population ageing in LMICs, highlighted by an increase in dementia-specific research in the past 10 years [112]. Also, across different LMIC settings there are high levels of low educational attainment/illiteracy in older people and there are often no norms for cognitive testing making MCI diagnosis challenging. Furthermore, there are typically very 
few specialist clinicians able to supervise this type of work in LMIC settings, with the exception of some countries like China.

\section{Strengths and Weaknesses}

The study has a number of strengths. We undertook a wide literature search capturing many of the different definitions of MCI. This allowed for a more comprehensive synthesis of the types of criteria used to diagnose MCI across the many different LMICs. Some studies however could still have been missed if they defined MCI outside the scope of the search. There are some weaknesses. First, the electronic search was undertaken in English and therefore studies published in other languages, including those common in LMICs such as Spanish, Portuguese and French could have been missed if they were not recoded in EMBASE, Pubmed or PsycInfo. We minimised the risk of not capturing Chinese articles by including findings from a recent systematic review on MIC prevalence in China[7]. Structuring the search this way could possibly explain the large number of MCI studies captured from China compared to other LMICs. This difference could also be due to variability in research investment into ageing and dementia. Second, we focused only on cross-sectional studies that reported MCI prevalence estimates. Therefore, we did not investigate whether MCI is predictive of future dementia in LMICs or what the risk factors for incident MCI are. As such, we are unable to make recommendations as to which criteria are the most "useful”. This was beyond the scope of the review. Last, given the paucity of research into ageing and dementia in LMIC settings we included any population-based study in the review; and, only four were population-representative [11, 44, 65, 93]. MCI prevalence results in non-representative samples must be viewed with caution as they may be biased for example by sampling (e.g. difference in location such as urban vs. rural) and differences in the profile of risk/protective factors (e.g. demographic, health and socio-economic status).

\section{Conclusion}

Numerous definitions of MCI have been proposed [113]. Determining which, if any, are suitable for application in LMICs will require an in-depth evaluation of not only how well they capture people with 
cognitive impairment, but also whether the condition is predictive of future dementia in these settings. To achieve this will require consensus on how MCI is defined particularly in settings with varying educational levels and amongst older people and varying cultural milieu and expectations resulting in challenges in MCI case identification. Nevertheless, given the high burden of dementia now seen in LMIC s, identification of these higher risk individuals at a stage where intervention could take place is likely to have a high impact on the burden of disease associated with cognitive impairment and dementia in these settings. Thus, to further understand MCI prevalence in these settings there is an urgent need for more high quality, population representative MCI prevalence studies, particularly in countries classified as low income.

\section{Conflict of Interests / Disclosure Statement}

The authors have no conflict of interest to report.

\section{Acknowledgments (including sources of support)}

This project was funded by a Newcastle-Monash Universities SEED award and as part of NIHR Global Group: DePEC (Grant Number: 16/137/62).

\section{Contributor Statement}

BCM conceptualised the study. CVA, CR, and YZ screened and selected the studies. AMG, AS, BCMS and CVA extracted the data. CVA and BCM drafted the initial manuscript, with a critical review by AMG. MS developed the forest plots. SMP, DM, YCS, MP, LR, MS, CR, SC, AS provided feedback and further revised the manuscript. All authors read and approved the final manuscript. 


\section{References}

[1] Bischkopf J, Busse A, Angermeyer MC (2002) Mild cognitive impairment--a review of prevalence, incidence and outcome according to current approaches. Acta Psychiatr Scand 106, 403-414.

[2] Nie H, Xu Y, Liu B, Zhang Y, Lei T, Hui X, Zhang L, Wu Y (2011) The prevalence of mild cognitive impairment about elderly population in China: A meta-analysis. 26, 558-563.

[3] Roberts R, Knopman DS (2013) Classification and epidemiology of MCI. Clin Geriatr Med 29, 753-772.

[4] Alexander M, Perera G, Ford L, Arrighi HM, Foskett N, Debove C, Novak G, Gordon MF (2015) Age-Stratified Prevalence of Mild Cognitive Impairment and Dementia in European Populations: A Systematic Review. J Alzheimers Dis 48, 355-359.

[5] Hu C, Yu D, Sun X, Zhang M, Wang L, Qin H (2017) The prevalence and progression of mild cognitive impairment among clinic and community populations: A systematic review and meta-analysis. Int Psychogeriatr 29, 1595-1608.

[6] Ward A, Arrighi HM, Michels S, Cedarbaum JM (2012) Mild cognitive impairment: disparity of incidence and prevalence estimates. Alzheimers Dement 8, 14-21.

[7] Xue J, Li J, Liang J, Chen S (2018) The Prevalence of Mild Cognitive Impairment in China: A Systematic Review. Aging Dis 9, 706-715.

[8] Petersen RC, Smith GE, Waring SC, Ivnik RJ, Tangalos EG, Kokmen E (1999) Mild cognitive impairment: clinical characterization and outcome. Arch Neurol 56, 303-308.

[9] Sosa AL, Albanese E, Stephan BC, Dewey M, Acosta D, Ferri CP, Guerra M, Huang Y, Jacob KS, Jimenez-Velazquez IZ, Rodriguez JJ, Salas A, Williams J, Acosta I, Gonzalez-Viruet M, Hernandez MA, Shuran L, Prince MJ, Stewart R (2012) Prevalence, distribution, and impact of mild cognitive impairment in Latin America, China, and India: a 10/66 population-based study. PLoS Med 9, e1001170.

[10] Albert MS, DeKosky ST, Dickson D, Dubois B, Feldman HH, Fox NC, Gamst A, Holtzman DM, Jagust WJ, Petersen RC (2011) The diagnosis of mild cognitive impairment due to Alzheimer's disease: Recommendations from the National Institute on Aging-Alzheimer's Association workgroups on diagnostic guidelines for Alzheimer's disease. Alzheimers Dement 7, 270279.

[11] Vancampfort D, Stubbs B, Lara E, Vandenbulcke M, Swinnen N, Koyanagi A (2017) Mild cognitive impairment and physical activity in the general population: Findings from six lowand middle-income countries. Exp Gerontol 100, 100-105.

[12] Koyanagi A, Veronese N, Stubbs B, Vancampfort D, Stickley A, Oh H, Shin J, Jackson S, Smith L, Lara E (2019) Food Insecurity Is Associated with Mild Cognitive Impairment among MiddleAged and Older Adults in South Africa: Findings from a Nationally Representative Survey. Nutrients 11, 749.

[13] Saunders S, Ritchie K, Russ TC, Muniz-Terrera G, Ritchie CW (2018) Evolution and future directions for the concept of mild cognitive impairment. Int Psychogeriatr 30, 1431-1434.

[14] Livingston G, Sommerlad A, Orgeta V, Costafreda SG, Huntley J, Ames D, Ballard C, Banerjee S, Burns A, Cohen-Mansfield J, Cooper C, Fox N, Gitlin LN, Howard R, Kales HC, Larson EB, Ritchie K, Rockwood K, Sampson EL, Samus Q, Schneider LS, Selbaek G, Teri L, Mukadam N (2017) Dementia prevention, intervention, and care. Lancet 390, 2673-2734.

[15] Mukadam N, Sommerlad A, Huntley J, Livingston G (2019) Population attributable fractions for risk factors for dementia in low-income and middle-income countries: an analysis using cross-sectional survey data. Lancet Glob Health 7, e596-e603.

[16] Moher D, Liberati A, Tetzlaff J, Altman DG, medicine PGJP (2009) Preferred reporting items for systematic reviews and meta-analyses: the PRISMA statement. PLoS Med 6, e1000097.

[17] Stroup DF, Berlin JA, Morton SC, Olkin I, Williamson GD, Rennie D, Moher D, Becker BJ, Sipe TA, Thacker SB (2000) Meta-analysis of observational studies in epidemiology: a proposal for 
reporting. Meta-analysis Of Observational Studies in Epidemiology (MOOSE) group. JAMA 283, 2008-2012.

[18] WBG, Low and middle income - income level, The World Bank Group, https://data.worldbank.org/income-level/low-and-middle-income, Accessed 25/1/2018.

[19] Hoy D, Brooks P, Woolf A, Blyth F, March L, Bain C, Baker P, Smith E, Buchbinder R (2012) Assessing risk of bias in prevalence studies: modification of an existing tool and evidence of interrater agreement. J Clin Epidemiol 65, 934-939.

[20] Hai S, Dong B, Liu Y, Zou Y (2012) Occurrence and risk factors of mild cognitive impairment in the older Chinese population: a 3-year follow-up study. Int J Geriatr Psychiatry 27, 703-708.

[21] Henao-Arboleda E, Aguirre-Acevedo DC, Munoz C, Pineda DA, Lopera F (2008) Prevalence of mild cognitive impairment, amnestic-type, in a colombian population. [Spanish]. Rev Neurol 46, 709-713.

[22] Juarez-Cedillo T, Sanchez-Arenas R, Sanchez-Garcia S, Garcia-Pena C, Hsiung GYR, Sepehry AA, Beattie BL, Jacova C (2013) Prevalence of mild cognitive impairment and its subtypes in the Mexican population. Dement Geriatr Cogn Disord 34, 5-6.

[23] Ogunniyi A, Adebiyi AO, Adediran AB, Olakehinde OO, Siwoku AA (2016) Prevalence estimates of major neurocognitive disorders in a rural Nigerian community. Brain Behav 6, e00481.

[24] Qiu CJ, Tang MN, Zhang W, Han HY, Dai J, Lu J, Wu S, Wang SH, Chen JM, Guo L, Ding YQ, Li SX, Liu XH (2003) The prevalence of mild cognitive impairment among residents aged 55 or over in Chengdu area. [Chinese]. Chin J Epidemiol 24, 1104-1107.

[25] Tiwari SC, Srivastava G, Tripathi RK, Pandey NM, Agarwal GG, Pandey S, Tiwari S (2013) Prevalence of psychiatric morbidity amongst the community dwelling rural older adults in northern India. Indian J Med Res 138, 504-514.

[26] Wang T, Xiao S, Chen K, Yang C, Dong S, Cheng Y, Li X, Wang J, Zhu M, Yang F, Li G, Su N, Liu $Y$, Dai J, Zhang M (2017) Prevalence, Incidence, Risk and Protective Factors of Amnestic Mild Cognitive Impairment in the Elderly in Shanghai. Curr Alzheimer Res 14, 460-466.

[27] Xu S, Xie B, Song M, Yu L, Wang L, An C, Zhu Q, Han K, Zhao X, Zhang R, Dong L, Chai N, Gao $Y$, Zhang $Q$, Wang $X$ (2014) High prevalence of mild cognitive impairment in the elderly: a community-based study in four cities of the Hebei province, china. Neuroepidemiology $\mathbf{4 2}$, 123-130.

[28] Pan H, Wang J, Wu M, Cheng J (2012) Study on prevalence rate and quality of life of elderly patients with mildcognitive impairment in community. Chin J Prac Nurs 29, 6-9.

[29] Gao LW, Jiang L, Gao YS, Nie HW, Y X (2011) Prevalence of mild cognitive impairment and its risk factors among elderly people in Canglang District of Suzhou City. J Occup Health 27, 2676-2678.

[30] Huang L, Han JF, Liu AP, B L (2007) The study and analysis on mild cognitive impairment of the elderly in communities. Mod Nurs 13, 2678-2680.

[31] Lao ML, Zhang HY, Luo G, Yi XN, Huang YD, Wu ZH (2011) Prevalence of mild cognitive impairment among 55-years old or over individuals in Hainan Island. Hainan Med J 22, 112 114.

[32] Liao B, Gao M, Xiong LH, Yi GP, Li Y, Wan SL, al. e (2012) The early evaluation and intervention strategies of mild cognitive impairment in Yichun area. J Yichun Coll 24, 77-79.

[33] Guo M, Gao L, Zhang G, Li Y, Xu S, Wang Z, Qu Q, Guo F (2012) Prevalence of dementia and mild cognitive impairment in the elderly living in nursing and veteran care homes in Xi'an, China. J Neurol Sci 312, 39-44.

[34] Qin HY, Chen DH, ZW Q (2014) Investigation of mild cognitive impairment and its risk factors among 55 years old and above residents in Shanghai. J Clin Psychiatry 24, 155-158.

[35] Song XZ, Chen JH, LP H (2012) Investigation on correlation between prevalence of the mild cognitive impairment and eation habit in elderly in the communities of Shunde-city. Int Med Health Guid News 18, 1715-1718. 
[36] Su XB, Hua QZ, Zhang L, LI NN, Chen JH, LP Z (2013) Influencing factors of mild cognitive impairment of seniors in communitiew of Xi'an. J Nurs 20, 6-9.

[37] Tang Z, Zhang XQ, Wu XG, Liu HJ, Diao L, Guan SC, al. e (2007) Prevalence of the mild cognitive impairment among eldrly in Beijing. Chin Ment Health J 21, 116-118.

[38] Tong JF, Guo SY, Tao XJ, Guo JX, Tian Y, Xia BJ, al. e (2013) The elderly patients with mild cognitive impairment in the community of Tangshan. Chin J Helth Psychol 21, 1642-1644.

[39] Yin SQ, Nie HW, Y X (2011) The prevalence and risk factors of mild cognitive impairment among the aged in Huzhou. Chin Gen Pract 14, 4145-4147.

[40] Zhu KH, H L (2015) Analysis of influencing factors of mild cognitive impairment in elderly population. Chin J Pract Nerv Dis 18, 52-54.

[41] Zhang $Y(2011)$ The study on the present situation investigating risk factors and early intervention of mild cognitive impairment in the elderly, MSc Thesis. Soochow University.

[42] Wang Q (2012) A study on the prevalence and risk factors of mild cognitive impairment among the elderly in Tianjin community, MSc Thesis. Tianjin Medical University.

[43] Li X, Ma C, Zhang J, Liang Y, Chen Y, Chen K, Wang J, Zhang Z, Wang Y, Beijing Ageing Brain Rejuvenation I (2013) Prevalence of and potential risk factors for mild cognitive impairment in community-dwelling residents of Beijing. J Am Geriatr Soc 61, 2111-2119.

[44] Jia J, Zhou A, Wei C, Jia X, Wang F, Li F, Wu X, Mok V, Gauthier S, Tang M, Chu L, Zhou Y, Zhou C, Cui Y, Wang Q, Wang W, Yin P, Hu N, Zuo X, Song H, Qin W, Wu L, Li D, Jia L, Song J, Han Y, Xing Y, Yang P, Li Y, Qiao Y, Tang Y, Lv J, Dong X (2014) The prevalence of mild cognitive impairment and its etiological subtypes in elderly Chinese. Alzheimers Dement 10, 439-447.

[45] Ding D, Zhao Q, Guo Q, Meng H, Wang B, Luo J, Mortimer JA, Borenstein AR, Hong Z (2015) Prevalence of mild cognitive impairment in an urban community in China: a cross-sectional analysis of the Shanghai Aging Study. Alzheimers Dement 11, 300-309 e302.

[46] Janelidze M, Mikeladze N, Bochorishvili N, Dzagnidze A, Kapianidze M, Mikava N, Khatiashvili I, Mirvelashvili E, Shiukashvili N, Lynch J, Nadareishvili Z (2018) Mild Cognitive Impairment in Republic of Georgia. Gerontol Geriatr Med 4, 1-10.

[47] Lee LK, Shahar S, Chin AV, Mohd Yusoff NA, Rajab N, Aziz SA (2012) Prevalence of gender disparities and predictors affecting the occurrence of mild cognitive impairment (MCI). Arch Gerontol Geriatr 54, 185-191.

[48] Ma F, Wu T, Zhao J, Ji L, Song A, Zhang M, Huang G (2016) Prevalence of mild cognitive impairment and its subtypes among Chinese older adults: Role of vascular risk factors. Dement Geriatr Cogn Disord 41, 261-272.

[49] Paddick SM, Kisoli A, Samuel M, Higginson J, Gray WK, Dotchin CL, Longdon AR, Teodorczuk A, Chaote P, Walker RW (2015) Mild cognitive impairment in rural Tanzania: Prevalence, profile, and outcomes at 4-year follow-up. Am J Geriatr Psychiatry 23, 950-959.

[50] Pilleron S, Jesus P, Desport JC, Mbelesso P, Ndamba-Bandzouzi B, Clement JP, Dartigues JF, Preux PM, Guerchet M (2015) Association between mild cognitive impairment and dementia and undernutrition among elderly people in Central Africa: some results from the EPIDEMCA (Epidemiology of Dementia in Central Africa) programme. Br J Nutr 114, 306-315.

[51] Rao D, Luo X, Tang M, Shen Y, Huang R, Yu J, Ren J, Cheng X, Lin K (2018) Prevalence of mild cognitive impairment and its subtypes in community-dwelling residents aged 65 years or older in Guangzhou, China. Arch Gerontol Geriatr 75, 70-75.

[52] Su X, Shang L, Xu Q, Li N, Chen J, Zhang L, Zhang L, Hua Q (2014) Prevalence and predictors of mild cognitive impairment in Xi'an: a community-based study among the elders. Plos One 9, e83217.

[53] Vanoh D, Shahar S, Din NC, Omar A, Vyrn CA, Razali R, Ibrahim R, Hamid TA (2016) Predictors of poor cognitive status among older Malaysian adults: baseline findings from the LRGS TUA cohort study. Aging Clin Exp Res 29, 173-182. 
[54] Fang GZ, Chen XP, $\sqcup Y(2009)$ The prevalence rate of mild cognitive impairment and its related factors in community elderly in Hangzhou. Chin J Ger 28, 512- 515.

[55] Tsoy RT, Turuspekova ST, Klipitskaya NK, Mereke A, Cumming RG (2019) Prevalence of Mild Cognitive Impairment Among Older People in Kazakhstan and Potential Risk Factors: A Crosssectional Study. Alzheimer Dis Assoc Disord 33, 136-141.

[56] Fang H, JH S (2015) Investigation of the elderly with mild cognitive impairment in Shanghai Zhoujiaqiao Community. Med Health Care 23, 5-8.

[57] Sun HY, Qu QM, Liu J, Zhang J, Guo X, Jla L, al. e (2016) The epidemiological study of ethnic disparity in risk factors for mild cognitive impairment between Mongolia and Han population in baotou, Inner Mongolia. J Apoplexy Nerv Dis 33, 454-456.

[58] Zhang JA, Jiang H, Wang FC, LL G (2013) Investigation and Analysis on mild cognitive impaiment among the elderly in the communities of Taicang city. Pract Geriatr 27, 859-862.

[59] Brucki SMD, Nitrini R (2014) Cognitive impairment in individuals with low educational level and homogeneous sociocultural background. Dement Neuropsychol 8, 345-350.

[60] Cesar KG, Brucki SMD, Takada LT, Nascimento LFC, Gomes CMS, Almeida MCS, Oliveira MO, Porto FHG, Senaha MLH, Bahia VS, Silva TBL, lanof JN, Spindola L, Schmidt MT, Jorge MS, Vale PHF, Cecchini MA, Cassimiro L, Soares RT, Goncalves MR, Martins ACS, Dare P, Smid J, Porto CS, Carthery-Goulart MT, Yassuda MS, Mansur LL, Nitrini R (2016) Prevalence of cognitive impairment without dementia and dementia in Tremembe, Brazil. Alzheimer Dis Assoc Disord 30, 264-271.

[61] Dominguez J, Fe de Guzman M, Reandelar M, Thi Phung TK (2018) Prevalence of Dementia and Associated Risk Factors: A Population-Based Study in the Philippines. J Alzheimers Dis 63, 1065-1073.

[62] Fei M, Qu YC, Wang T, Yin J, Bai JX, Ding QH (2009) Prevalence and distribution of cognitive impairment no dementia (CIND) among the aged population and the analysis of sociodemographic characteristics: The community-based cross-sectional study. Alzheimer Dis Assoc Disord 23, 130-138.

[63] Guerchet M, Houinato D, Paraiso MN, von Ahsen N, Nubukpo P, Otto M, Clement JP, Preux PM, Dartigues JF (2009) Cognitive impairment and dementia in elderly people living in rural Benin, west Africa. Dement Geriatr Cogn Disord 27, 34-41.

[64] Guerchet M, M'Belesso P, Mouanga AM, Bandzouzi B, Tabo A, Houinato DS, Paraiso MN, Cowppli-Bony P, Nubukpo P, Aboyans V, Clement JP, Dartigues JF, Preux PM (2010) Prevalence of dementia in elderly living in two cities of Central Africa: the EDAC survey. Dement Geriatr Cogn Disord 30, 261-268.

[65] Mejia-Arango S, Gutierrez LM (2011) Prevalence and incidence rates of dementia and cognitive impairment no dementia in the Mexican population: data from the Mexican Health and Aging Study. J Aging Health 23, 1054-1074.

[66] Shi Z, Zhang Y, Yue W, Liu M, Huo YR, Liu S, Liu S, Xiang L, Liu P, Lu H, Wang J, Ji Y (2013) Prevalence and clinical predictors of cognitive impairment in individuals aged 80 years and older in rural China. Dement Geriatr Cogn Disord 36, 171-178.

[67] Zhang Y, Shi Z, Liu M, Liu S, Yue W, Liu S, Xiang L, Lu H, Liu P, Wisniewski T, Wang J, Ji Y (2014) Prevalence of cognitive impairment no dementia in a rural area of Northern China. Neuroepidemiology 42, 197-203.

[68] Lei M, Huang W, Yang J, Gao L, Wei L, al. e (2008) Prevalence of mild cognitive impairment old people in urban and rural areas of Guizhou province. Chin Ment Health J 22, 387-391.

[69] Inocian E, Patalagsa JG (2016) Cognitive impairment in older people living in the community. Nurs Older People 28, 25-30.

[70] Khedr E, Fawi G, Abbas MAA, Mohammed TA, El-Fetoh NA, Al Attar G, Noaman M, Zaki AF (2015) Prevalence of mild cognitive impairment and dementia among the elderly population of qena governorate, upper Egypt: A community-based study. J Alzheimers Dis 45, 117-126. 
[71] Ding D, Zhao Q, Guo Q, Meng H, Wang B, Luo J, Mortimer JA, Borenstein AR, Hong Z (2015) Prevalence of mild cognitive impairment in an urban community in China: A cross-sectional analysis of the Shanghai Aging Study. Alzheimers Dement 11, 300-309.e302.

[72] Guo XY, Zhao LM, Li XM, Q Y (2013) Prevalence of mild cognitive impairment among rural Chinese elderly. Chin J Mult Organ Dis Elderly 12, 904-907.

[73] Huang RY, Tang MN, Ma C, Guo YB, Han HY, Huang JM, al. e (2008) The prevalence of mild cognitive impairment of residents aged 60 years and over in the urban and rural areas in Guangdong. Chin J Nerv Ment Dis 34, 533-537.

[74] Li J (2013) Survey of mild cognitive impairment in old people in community of Jinan city. Chin Nurs Research 27, 2196-2197.

[75] Wang ZQ, Zhuang MH, Lin YQ, Ding CH, H W (2014) The study on present situation investigation of mild cognitve impairment among elderly people in Zhoushan Island city. Zhejiang Med J 8, 707-709.

[76] Wu B, Zhang LY, Su YL, Dang YH, JX H (2012) Investigation on mild cognitive impairment among elderly in urban community of Xi'an. Chin J Rehabil Theory Pract 18, 605-607.

[77] Zhang WX, Li CP, Tian F, Wang Y, Liang YJ, X L (2015) The value of MoCA (Beijing) in screening mild cognitive impairment among old people in rural. Chin J Gerontol 35, 4016-4018.

[78] Zhang XQ, H Z (2014) Prevalence and factors associated with mild cognitive impairment among the elderly in Changsha Communities. Chin Gen Pract 17, 1031-1035.

[79] Zhao CS, Gao L, JN F (2015) Present situation and risk factors of mild cognitive impairment of 60-years old or over people in Jilin area. Chin Rural Health Serv Adm 35, 1434-1437.

[80] Zhou DM, Chen Q, Sui CY, M Y (2016) Investigation on the prevalence of mild cognitive impairment in the elderly in Changji city. Chin Community Doct 32, 178-183.

[81] Zhou DS, Xu YE, ZM C (2011) Prevalence of mild cognitive impairment among the elderly. Chin J Public Health 27, 1375-1377.

[82] Zhou XH, Zhu XQ, Barhematy K, Yue YH, Zhao RJ, Xing SF, al. e (2009) Cross-sectional study of the mild cognitive impairment among elderly in Xinjiang Uygur and Han ethnic groups. Chin J Geriatr 28, 865-869.

[83] Zhu XQ, Zhou XH, Barheimaty K, Yue YH, Zhao RJ, Xing SF, al. e (2009) Study of prevalence of the mild cognitive impairment among elderly in the communities of Urumqi city. J Xinjiang Med Univ 32, 578-584.

[84] Zhu YP, Chen MF, BH Z (2013) A prevalence study on mild cognitive impairment among elderly population in Zhejiang provience. Chin J Epidemiol 34, 475-477.

[85] Mohan D, lype T, Varghese S, Usha A, Mohan M (2019) A cross-sectional study to assess prevalence and factors associated with mild cognitive impairment among older adults in an urban area of Kerala, South India. BMJ Open 9, e025473.

[86] Lu H, Wang X-D, Shi Z, Yue W, Zhang Y, Liu S, Liu S, Zhao L, Xiang L, Zhang Y, Guan Y, Su W, Li Z, Wang J, Wisniewski T, Ji Y (2019) Comparative analysis of cognitive impairment prevalence and its etiological subtypes in a rural area of northern China between 2010 and 2015. Sci Rep 9, 851.

[87] Ruan Q, Xiao F, Gong K, Zhang W, Zhang M, Ruan J, Zhang X, Chen Q, Yu Z (2020) Prevalence of Cognitive Frailty Phenotypes and Associated Factors in a Community-Dwelling Elderly Population. J Nutr Health Aging 24, 172-180.

[88] Dimitrov I, Tzourio C, Milanov I, Deleva N, Traykov L (2012) Prevalence of dementia and mild cognitive impairment in a Bulgarian urban population. Am J Alzheimers Dis Other Demen 27, 131-135.

[89] Chu AQ, Liang XN, Chen YH, Gu PF, HW Q (2015) Prevalence and risk factors of mild cognitive impairment and dementia in community elderly. Chin J of Clin Neuro 23, 673-677.

[90] Xiong Y, Miao RJ, Wang QQ, Zhou L, Gao L, F M (2013) Prevalence and influencing factors of $\mathrm{MCl}$ among community elderly in Tianjin city. Chin J Public Health 29, 1-4. 
[91] Das SK, Bose P, Biswas A, Dutt A, Banerjee TK, Hazra AM, Raut DK, Chaudhuri A, Roy T (2007) An epidemiologic study of mild cognitive impairment in Kolkata, India. Neurology 68, 20192026.

[92] Saha SK, Sanyal D, Bhattacharyya A, Bhattacharyya R, Barman N, Mukherjee A (2010) A study on cognitive status of 50 years and above aged non-demented women in a rural area of West Bengal. J Indian Med Assoc 108, 726-729.

[93] Koyanagi A, Veronese N, Stubbs B, Vancampfort D, Stickley A, Oh H, Shin JI, Jackson S, Smith L, Lara E (2019) Food Insecurity Is Associated with Mild Cognitive Impairment among MiddleAged and Older Adults in South Africa: Findings from a Nationally Representative Survey. Nutrients 11, 749.

[94] Wang ZZ, Liu L, Huang YQ, Ding L, WR M (2016) The status of mild cognitive impairment in the Hui and Han people aged 55 years and above in Ningxia. Chin J Gerantol 36, 4601-4603.

[95] Wang ZZ, Ding L, Liu L, Li T, Ma WR, JL Z (2013) The present situation of mild cognitive impairment among 55-years old or over individuals of Hui and Han nationalities and its relationship with hormone. Chin J Nerv Ment Dis 39, 427-430.

[96] Hu R, Zhao SG, Wang DS, Wen SR, Niu GM, al. e (2012) A prevalence study on mild cognitive impairment among elderly population of Mongolian and Han nationalities in a pastrial area of Inner Mongolia. Chin J Epidemiol 33, 364-367.

[97] Petersen RC (2004) Mild cognitive impairment as a diagnostic entity. J Intern Med 256, 183194.

[98] Petersen RC, Caracciolo B, Brayne C, Gauthier S, Jelic V, Fratiglioni L (2014) Mild cognitive impairment: a concept in evolution. J Intern Med 275, 214-228.

[99] Petersen RC, Doody R, Kurz A, Mohs RC, Morris JC, Rabins PV, Ritchie K, Rossor M, Thal L, Winblad B (2001) Current concepts in mild cognitive impairment. Arch Neurol 58, 1985-1992.

[100] Petersen RC, Morris JC (2005) Mild cognitive impairment as a clinical entity and treatment target. Arch Neurol 62, 1160-1163.

[101] Petersen RC, Smith GE, Waring SC, Ivnik RJ, Kokmen E, Tangelos EG (1997) Aging, memory, and mild cognitive impairment. Int Psychogeriatr 9, 65-69.

[102] Petersen RC, Stevens JC, Ganguli M, Tangalos EG, Cummings JL, DeKosky ST (2001) Practice parameter: early detection of dementia: mild cognitive impairment (an evidence-based review). Report of the Quality Standards Subcommittee of the American Academy of Neurology. Neurology 56, 1133-1142.

[103] Winblad B, Palmer K, Kivipelto M, Jelic V, Fratiglioni L, Wahlund LO, Nordberg A, Bäckman L, Albert M, Almkvist O (2004) Mild cognitive impairment-beyond controversies, towards a consensus: report of the International Working Group on Mild Cognitive Impairment. J Intern Med 256, 240-246.

[104] Bell CC (1994) DSM-IV: Diagnostic and Statistical Manual of Mental Disorders. JAMA 272, 828-829.

[105] Portet F, Ousset PJ, Visser PJ, Frisoni GB, Nobili F, Scheltens P, Vellas B, Touchon J (2006) Mild cognitive impairment $(\mathrm{MCl})$ in medical practice: a critical review of the concept and new diagnostic procedure. Report of the $\mathrm{MCl}$ Working Group of the European Consortium on Alzheimer's Disease. J Neurol Neurosurg Psychiatry 77, 714-718.

[106] Vancampfort D, Stubbs B, Firth J, Smith L, Swinnen N, Koyanagi A (2019) Associations between handgrip strength and mild cognitive impairment in middle-aged and older adults in six low- and middle-income countries. Int J Geriatr Psychiatry 34, 609-616.

[107] Chong CP, Shahar S, Haron H, Din NC (2019) Habitual sugar intake and cognitive impairment among multi-ethnic Malaysian older adults. Clin Interv Aging 14, 1331-1342.

[108] Zhang Y, Guan Y, Shi Z, Yue W, Liu S, Liu S, Lu H, Zhao L, Zhang Y, Su W, Ji Y (2019) Sex Differences in the Prevalence of and Risk Factors for Cognitive Impairment No Dementia among the Elderly in a Rural Area of Northern China: A Population-Based Cross-Sectional Study. Neuroepidemiology 52, 25-31. 
[109] Wang Y, Song M, Yu L, Wang L, An C, Xun S, Zhao X, Gao Y, Wang X (2015) Mild cognitive impairment: vascular risk factors in community elderly in four cities of Hebei Province, China. PLoS One 10, e0124566.

[110] Stephan BC, Matthews FE, McKeith IG, Bond J, Brayne C, Medical Research Council Cognitive F, Aging S (2007) Early cognitive change in the general population: how do different definitions work? J Am Geriatr Soc 55, 1534-1540.

[111] Pessoa RMP, Bomfim AJL, Ferreira BLC, Chagas MHN (2019) Diagnostic criteria and prevalence of mild cognitive impairment in older adults living in the community: a systematic review and meta-analysis. Arch Clin Psychiatry (São Paulo) 46, 72-79.

[112] Patterson C, World Alzheimer Report 2018 - The state of the art of dementia research: New frontiers, https://www.alz.co.uk/research/WorldAlzheimerReport2018.pdf, Accessed 25/07/2020.

[113] Matthews FE, Stephan BC, McKeith IG, Bond J, Brayne C, Medical Research Council Cognitive F, Ageing $S$ (2008) Two-year progression from mild cognitive impairment to dementia: to what extent do different definitions agree? J Am Geriatr Soc 56, 1424-1433.

[114] Jia JP, Zhou AH, Wei CB, Jia XF, Wang F, Li F, al. e (2014) The prevalence of mild cognitive impairment and its etiological subtypes in elderly Chinese. Alzheimers Dement 10, 439-447. 
Table 1 Study characteristics and MCI prevalence arranged by definition (ordered by age [lowest to highest])

\begin{tabular}{|c|c|c|c|c|c|c|c|c|}
\hline \multirow[b]{2}{*}{ Author } & \multirow[b]{2}{*}{ Location } & \multirow[b]{2}{*}{$\begin{array}{l}\text { Income } \\
\text { Class }\end{array}$} & \multirow[b]{2}{*}{$\begin{array}{l}\text { Age } \\
\text { (years) }\end{array}$} & \multirow[b]{2}{*}{$\begin{array}{l}\text { Summary population } \\
\text { characteristics }\end{array}$} & \multicolumn{4}{|c|}{ Mild cognitive impairment (MCI) } \\
\hline & & & & & $\begin{array}{l}\text { MCI } \\
\text { definition }\end{array}$ & $\begin{array}{l}\text { Total } \\
\text { sample } \\
\text { size }\end{array}$ & Cases & $\begin{array}{l}\text { Prevalence \% } \\
(95 \% \text { CI) }\end{array}$ \\
\hline \multicolumn{9}{|c|}{ MCI ACCORDING TO PETERSEN CRITERIA[8, 99, 101, 102] (n=26 studies) } \\
\hline $\begin{array}{l}\text { Henao-Arboleda, } \\
2008[21]\end{array}$ & Columbia & UMIC & $\geq 50$ & $\begin{array}{l}\text { Residents of metropolitan area of } \\
\text { Medellin }\end{array}$ & aMCI & 848 & 82 & $9.7(7.6-11.7)$ \\
\hline Lao, 2011[31] & China & UMIC & $\geq 55$ & $\begin{array}{l}\text { Non-demented residents of } \\
\text { Hainan province }\end{array}$ & MCI & 7665 & 326 & $4.25(3.80-4.68)$ \\
\hline \multirow{4}{*}{ Li, 2013 [43] } & \multirow{4}{*}{ China } & \multirow{4}{*}{ UMIC } & \multirow{4}{*}{$\geq 55$} & \multirow{4}{*}{$\begin{array}{l}\text { Non-demented residents of } \\
\text { Beijing with an MMSE } \geq 24 \text { (The } \\
\text { Beijing Ageing Brain } \\
\text { Rejuvenation Initiative: BABRI) }\end{array}$} & All MCI & 1,020 & 160 & 15.7 \\
\hline & & & & & aMCI-SD & 1,020 & 65 & 6.4 \\
\hline & & & & & aMCI-MD & 1,020 & 38 & 3.7 \\
\hline & & & & & naMCI & 1,020 & 57 & 5.6 \\
\hline Qin, 2014[34] & China & UMIC & $\geq 55$ & $\begin{array}{l}\text { Non-demented residents of } \\
\text { Shanghai }\end{array}$ & aMCI & 4086 & 612 & $14.98(13.88-16.02)$ \\
\hline Qiu, 2003 [24] & China & UMIC & $\geq 55$ & $\begin{array}{l}\text { Non-demented residents of } \\
\text { Chengdu }\end{array}$ & aMCI & 3910 & 92 & $2.40(1.88-2.80)$ \\
\hline Gao, 2011[29] & China & UMIC & $\geq 60$ & $\begin{array}{l}\text { Non-demented residents of a } \\
\text { community of Suzhou }\end{array}$ & aMCI & 1773 & 243 & $13.71(12.1-15.22)$ \\
\hline Huang, 2008[73] & China & UMIC & $\geq 60$ & $\begin{array}{l}\text { Non-demented residents of } \\
\text { Guangzhou }\end{array}$ & $\mathrm{aMCI}$ & 4697 & 257 & $5.47(4.82-6.09)$ \\
\hline \multirow{5}{*}{$\begin{array}{l}\text { Juarez-Cedillo, } \\
2013 \text { [22] }\end{array}$} & \multirow{5}{*}{ Mexico } & \multirow{5}{*}{ UMIC } & \multirow{5}{*}{$\geq 60$} & \multirow{5}{*}{$\begin{array}{l}\text { Residents, registered with family } \\
\text { medicine units (IMSS), of } \\
\text { Mexico City }\end{array}$} & All MCI & 2,944 & 190 & $6.5(5.6-7.4)$ \\
\hline & & & & & aMCI-SD & 2,944 & 71 & $2.4(1.9-3.0)$ \\
\hline & & & & & aMCI-MD & 2,944 & 75 & $2.6(2.0-3.1)$ \\
\hline & & & & & naMCI-SD & 2,944 & 35 & $1.2(0.8-1.6)$ \\
\hline & & & & & naMCI-MD & 2,944 & 9 & $0.3(0.1-0.5)$ \\
\hline Liao , 2012[32] & China & UMIC & $\geq 60$ & $\begin{array}{l}\text { Non-demented residents of } \\
\text { Yichun }\end{array}$ & aMCI & 399 & 41 & $10.28(7.30-13.10)$ \\
\hline Pan, 2012 [28] & China & UMIC & $\geq 60$ & $\begin{array}{l}\text { Non-demented residents of } \\
\text { Jinhua }\end{array}$ & aMCI & 897 & 154 & 17.17 (14.7-19.51) \\
\hline Song, 2012[35] & China & UMIC & $\geq 60$ & $\begin{array}{l}\text { Non-demented residents of a } \\
\text { district of Foshan }\end{array}$ & aMCI & 2279 & 167 & $7.33(6.26-8.34)$ \\
\hline Su, 2013[36] & China & UMIC & $\geq 60$ & Non-demented residents of Xian & aMCI & 796 & 145 & 18.22(15.53-20.76) \\
\hline Tang, 2007[37] & China & UMIC & $\geq 60$ & $\begin{array}{l}\text { Non-demented residents of } \\
\text { Beijing }\end{array}$ & $\mathrm{aMCI}$ & 1865 & 217 & 11.60(10.18-13.02) \\
\hline Tiwari, 2013[25] & India & LMIC & $\geq 60$ & $\begin{array}{l}\text { Residents of Malihabad and } \\
\text { Bakshi Ka Talab of Lucknow } \\
\text { district of the State of Uttar } \\
\text { Pradesh }\end{array}$ & All MCI & 2,146 & 98 & $4.6(3.7-5.5)$ \\
\hline Tong, 2013[38] & China & UMIC & $\geq 60$ & $\begin{array}{l}\text { Non-demented residents of } \\
\text { Tangshan }\end{array}$ & aMCI & 1575 & 200 & 12.7 \\
\hline Wang, 2012[42] & China & UMIC & $\geq 60$ & $\begin{array}{l}\text { Non-demented residents of } \\
\text { Tianjin }\end{array}$ & aMCI & 3678 & 408 & 11.1 \\
\hline Wang, 2017[26] & China & UMIC & $\geq 60$ & $\begin{array}{l}\text { Residents of rural and urban } \\
\text { areas in Shanghai }\end{array}$ & aMCI & 1,005 & 224 & 22.3 \\
\hline $\mathrm{Xu}, 2014[27]$ & China & UMIC & $\geq 60$ & $\begin{array}{l}\text { Non-demented residents of the } \\
\text { Hebei province }\end{array}$ & All MCI & 2,426 & 526 & $21.3(19.2-23.1)^{\ddagger}$ \\
\hline Yin, 2011[39] & China & UMIC & $\geq 60$ & $\begin{array}{l}\text { Non-demented residents of } \\
\text { Huzhou }\end{array}$ & aMCI & 2164 & 310 & $14.33(12.85-15.73)$ \\
\hline Zhang, 2011[41] & China & UMIC & $\geq 60$ & $\begin{array}{l}\text { Non-demented residents of } \\
\text { Suzhou }\end{array}$ & aMCI & 5388 & 691 & 12.8 \\
\hline $\begin{array}{l}\text { Zhu and } \mathrm{Li} \text {, } \\
\text { 2015[40] }\end{array}$ & China & UMIC & $\geq 60$ & $\begin{array}{l}\text { Non-demented residents of some } \\
\text { communities of Xinyang }\end{array}$ & $\mathrm{aMCI}$ & 1755 & 245 & $13.96(12.34-15.50)$ \\
\hline \multirow{5}{*}{ Jia, 2014[114] } & \multirow{5}{*}{ China } & \multirow{5}{*}{ UMIC } & \multirow{5}{*}{$\geq 65$} & \multirow{5}{*}{$\begin{array}{l}\text { Non-demented residents of } 5 \text { city } \\
\text { of China }\end{array}$} & All MCI & 10,276 & 2,137 & $19.5(18.8-20.3)$ ฯ \\
\hline & & & & & alzMCI & 10,276 & 630 & $5.6(5.2-6.0)$ \\
\hline & & & & & cvdMCI & 10,276 & 392 & $3.4(3.3-4.1)^{\pi}$ \\
\hline & & & & & vrfMCI & 10,276 & 507 & $4.6(4.2-5.0)^{\pi}$ \\
\hline & & & & & otherMCI & 10,276 & 608 & $5.6(5.2-6.1)^{\pi}$ \\
\hline M Guo, 2012[33] & China & UMIC & $\geq 65$ & Non-demented residents of Xian & aMCI & 264 & 35 & $13.26(9.17-17.14)$ \\
\hline & Cuba & UMIC & & & aMCI & 2,620 & 47 & $1.5(1.0-1.9)^{\dagger}$ \\
\hline & $\mathrm{DR}$ & UMIC & & & aMCI & 1,767 & 25 & $1.3(0.7-1.8)^{\dagger}$ \\
\hline & Peru & UMIC & & & aMCI & 1,767 & 55 & $2.6(1.9-3.3)^{\dagger}$ \\
\hline Sosa, 2012[9] & Venezuela & UMIC & $\geq 65$ & Residents of urban & aMCI & 1,820 & 22 & $1.0(0.7-1.4)^{\dagger}$ \\
\hline & Mexico & UMIC & & and rural settings & aMCI & 1,821 & 58 & $2.8(2.0-3.6)^{\dagger}$ \\
\hline & China & UMIC & & & aMCI & 2,014 & 16 & $0.6(0.3-0.9)^{\dagger}$ \\
\hline & India & LMIC & & & aMCI & 1,802 & 77 & $4.6(3.7-5.4)^{\dagger}$ \\
\hline $\begin{array}{l}\text { Ogunniyi, } 2016 \\
\text { [23] }\end{array}$ & Nigeria & UMIC & $\geq 65$ & & $\begin{array}{l}\text { All MCI } \\
\text { aMCI-SD }\end{array}$ & $\begin{array}{l}6613 \\
613\end{array}$ & $\begin{array}{l}111 \\
47\end{array}$ & $\begin{array}{l}18.4(14.9-21.9)^{*} \\
\text { n/a }\end{array}$ \\
\hline
\end{tabular}




\begin{tabular}{|c|c|c|c|c|c|c|c|c|}
\hline \multirow{5}{*}{ Author } & \multirow{5}{*}{ Location } & \multirow{5}{*}{$\begin{array}{l}\text { Income } \\
\text { Class }\end{array}$} & \multirow{5}{*}{$\begin{array}{l}\text { Age } \\
\text { (years) }\end{array}$} & \multirow{5}{*}{$\begin{array}{l}\text { Summary population } \\
\text { characteristics } \\
\text { Residents of the Lalupon } \\
\text { community, Oyo State (The } \\
\text { IDEA Study) }\end{array}$} & \multicolumn{4}{|c|}{ Mild cognitive impairment (MCI) } \\
\hline & & & & & $\begin{array}{l}\text { MCI } \\
\text { definition }\end{array}$ & $\begin{array}{l}\text { Total } \\
\text { sample } \\
\text { size }\end{array}$ & Cases & $\begin{array}{l}\text { Prevalence \% } \\
(95 \% \text { CI) }\end{array}$ \\
\hline & & & & & aMCI-MD & 613 & 45 & $\mathrm{n} / \mathrm{a}$ \\
\hline & & & & & naMCI-SD & 613 & 18 & $\mathrm{n} / \mathrm{a}$ \\
\hline & & & & & naMCI-MD & 613 & 1 & $\mathrm{n} / \mathrm{a}$ \\
\hline Hai, 2012 [20] & China & UMIC & $\geq 80$ & $\begin{array}{l}\text { Non-demented residents of } \\
\text { Chengdu }\end{array}$ & aMCI & 202 & 61 & 30.2 \\
\hline \multicolumn{9}{|c|}{ INTERNATIONAL WORKING GROUP (IWG) ON MCI CRITERIA $2004[97,98,100,103]$ (n=14 studies) } \\
\hline & & & & & All MCI & 2,985 & 601 & $20.1(18.7-21.5)$ \\
\hline Ding, 2015[45] & China & UMIC & $\geq 60$ & Non-demented community & aMCI & 2,985 & 393 & $13.2(12.0-14.4)$ \\
\hline & & & & & naMCI & 2,985 & 208 & $7.0(6.1-7.9)$ \\
\hline Fang, 2015[56] & China & UMIC & $\geq 60$ & $\begin{array}{l}\text { Non-demented residents of a } \\
\text { community of Shanghai }\end{array}$ & $\mathrm{aMCI}$ & 1059 & 137 & $12.90(10.9-14.9)$ \\
\hline Fang, 2009[54] & China & UMIC & $\geq 60$ & $\begin{array}{l}\text { Non-demented residents of } \\
\text { Hangzhou }\end{array}$ & MCI & 925 & 195 & $21.10(18.45-23.58)$ \\
\hline Tsoy, 2019[55] & Kazakhstan & UMIC & $\geq 60$ & $\begin{array}{l}\text { Residents from Almaty, } \\
\text { Kazakhstan }\end{array}$ & MCI & 662 & 201 & $30.4(26.9-33.9)$ \\
\hline Vanoh, 2016[53] & Malaysia & LMIC & $\geq 60$ & $\begin{array}{l}\text { Residents of four different states: } \\
\text { Perak, Selangor, Kelantan and } \\
\text { Johor (Towards Useful Ageing } \\
\text { Study) }\end{array}$ & $\mathrm{aMCI}$ & 1,993 & 315 & 15.8 \\
\hline Zhang, 2013[58] & China & UMIC & $\geq 60$ & $\begin{array}{l}\text { Non-demented residents of } \\
\text { Taicang }\end{array}$ & aMCI & 2460 & 450 & $18.29(16.76-19.74)$ \\
\hline Su, 2013 [52] & China & UMIC & $\geq 60$ & $\begin{array}{l}\text { Elderly of rural and urban areas } \\
\text { in Xi'an }\end{array}$ & $\mathrm{aMCI}$ & 796 & 145 & 18.2 \\
\hline \multirow{3}{*}{ Lee, 2012[47] } & \multirow{3}{*}{ Malaysia } & \multirow{3}{*}{ LMIC } & \multirow{3}{*}{$\geq 60$} & \multirow{3}{*}{ Residents of Kuala Lumpur } & All MCI & 318 & 67 & 21.1 \\
\hline & & & & & aMCI & 318 & 49 & 15.4 \\
\hline & & & & & naMCI & 318 & 18 & 5.7 \\
\hline \multirow{5}{*}{$\begin{array}{l}\text { Janelidze, } \\
\text { 2018[46] }\end{array}$} & \multirow{5}{*}{ Georgia } & \multirow{5}{*}{ LMIC } & \multirow{5}{*}{$\geq 65$} & \multirow{5}{*}{$\begin{array}{l}\text { Residents, without moderate to } \\
\text { severe cognitive impairment, } \\
\text { from urban (Tbilisi) and two } \\
\text { rural areas (Kakheti and Imereti) }\end{array}$} & All MCI ${ }^{\S}$ & 238 & 66 & 27.7 \\
\hline & & & & & aMCI & 238 & 38 & 16.0 \\
\hline & & & & & naMCI & 238 & 29 & 9.9 \\
\hline & & & & & aMCI-MD & 238 & 8 & 3.3 \\
\hline & & & & & naMCI-MD & 238 & 12 & 5.1 \\
\hline \multirow{5}{*}{ Мa, 2016[48] } & \multirow{5}{*}{ China } & \multirow{5}{*}{ UMIC } & \multirow{5}{*}{$\geq 65$} & & All MCI & 5,067 & 574 & $11.3(8.2-14.4)$ \\
\hline & & & & & aMCI-SD & 5,067 & 227 & $4.5(2.2-6.7)$ \\
\hline & & & & sixteen districts within the & aMCI-MD & 5,067 & 106 & $2.1(0.8-3.4)$ \\
\hline & & & & & naMCI-SD & 5,067 & 214 & $4.2(1.4-7.1)$ \\
\hline & & & & & naMCI-MD & 5,067 & 27 & $0.5(0.3-0.8)$ \\
\hline & CAR & LIC & & Residents of Bangui and Nola & All MCI & 9860 & 62 & 7.2 \\
\hline Pilleron, 2015[50] & ROC & LMIC & $\geq 65$ & $\begin{array}{l}\text { Residents of Brazzaville and } \\
\text { Gamboma }\end{array}$ & All MCI & 1913 & 56 & 6.1 \\
\hline & & & & & All MCI & 2,111 & 299 & 14.2 \\
\hline Rao, 2018[51] & China & UMIC & $\geq 65$ & Residents of Guangzhou & aMCI & 2,111 & 258 & 12.2 \\
\hline & & & & & naMCI & 2,111 & 41 & 2.0 \\
\hline Sun, 2016[57] & China & UMIC & $\geq 65$ & $\begin{array}{l}\text { Non-demented residents of } \\
\text { Baotou }\end{array}$ & MCI & 384 & 40 & $10.42(7.36-13.32)$ \\
\hline $\begin{array}{l}\text { Paddick, } \\
2015[49]\end{array}$ & Tanzania & LIC & $\geq 70$ & Residents of the Hai district & All MCI & 296 & 46 & $6.3(2.9-9.7) \|$ \\
\hline EUROPEAN COI & RTIUM ON & ZHEIM & 'S DISE & SE CRITERIA 2006[105] (n=2 st & es) & & & \\
\hline Mohan, 2019[85] & India & LMIC & $\geq 60$ & $\begin{array}{l}\text { Residents from } \\
\text { Thiruvananthapuram, Kerala }\end{array}$ & All MCI & 426 & 111 & $26.1(22.1-30.4)$ \\
\hline $\begin{array}{l}\text { Dimitrov, } 2012 \\
\text { [88] }\end{array}$ & Bulgaria & UMIC & $\geq 65$ & Residents from the city of Varna & All MCI & 540 & 36 & $6.7(4.6-8.8)$ \\
\hline NIA-AA CRITER & A 2011[10] (n= & tudies) & & & & & & \\
\hline & South Africa & UMIC & & & & & & \\
\hline & China & UMIC & & Nationally representative sample & & & & \\
\hline Vancamnfort & Ghana & LMIC & & of elderly without severe & & & & \\
\hline 2017[11] & India & LMIC & $\geq 50$ & $\begin{array}{l}\text { cognitive impairment (The WHU } \\
\text { Study on Global Ageing and }\end{array}$ & All MCI & 32,715 & 5,005 & $15.3(14.4-16.3)^{* *}$ \\
\hline & Mexico & UMIC & & Adult Health) & & & & \\
\hline & Russia & UMIC & & & & & & \\
\hline $\begin{array}{l}\text { Koyanagi, } \\
2019[93]\end{array}$ & South Africa & UMIC & $\geq 50$ & $\begin{array}{l}\text { Nationally representative sample } \\
\text { from nine provinces across South } \\
\text { Africa }\end{array}$ & All MCI & 3672 & 312 & $8.5(6.9-10.3)$ \\
\hline
\end{tabular}




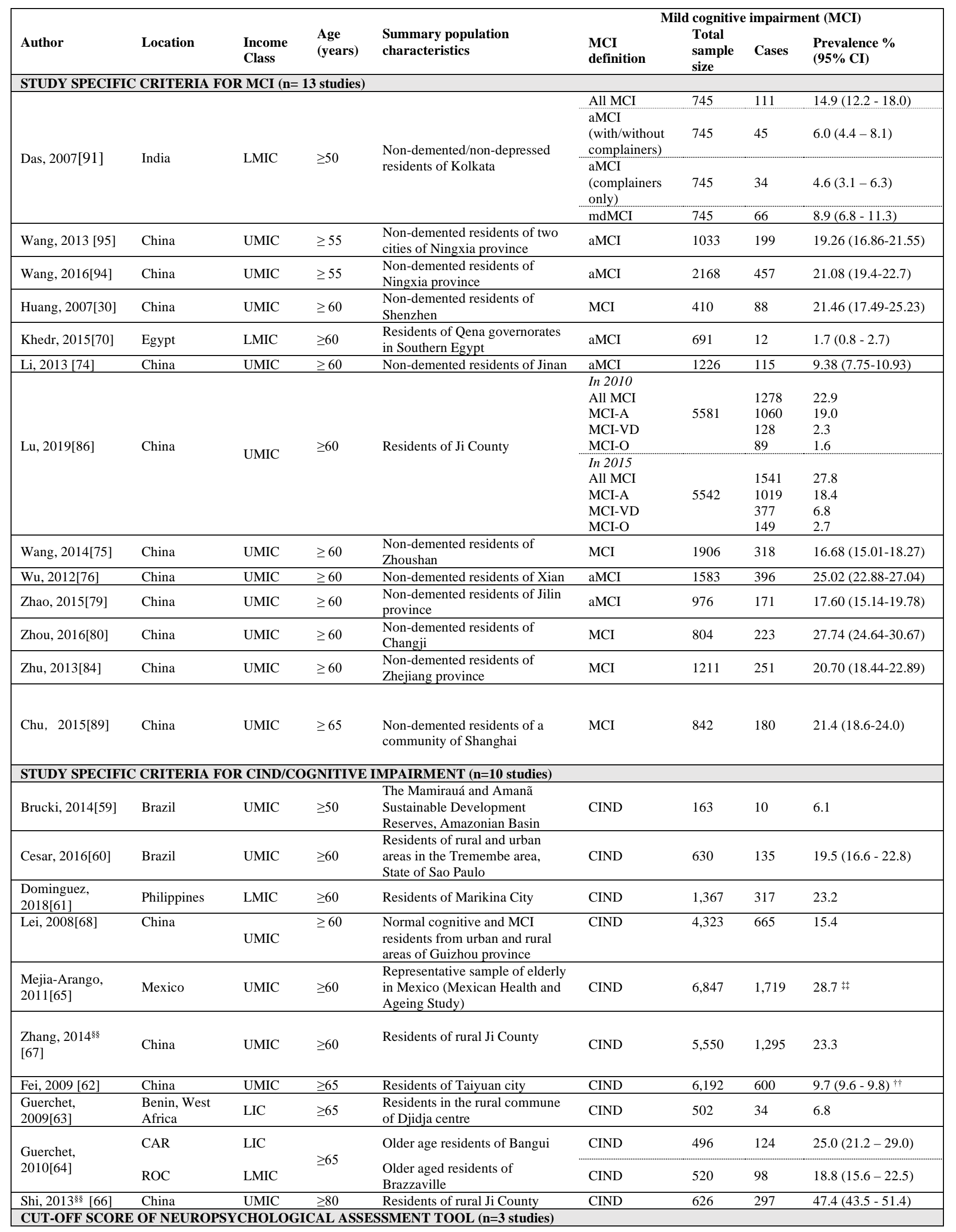




\begin{tabular}{|c|c|c|c|c|c|c|c|c|}
\hline \multirow[b]{2}{*}{ Author } & \multirow[b]{2}{*}{ Location } & \multirow[b]{2}{*}{$\begin{array}{l}\text { Income } \\
\text { Class }\end{array}$} & \multirow[b]{2}{*}{$\begin{array}{l}\text { Age } \\
\text { (years) }\end{array}$} & \multirow[b]{2}{*}{$\begin{array}{l}\text { Summary population } \\
\text { characteristics }\end{array}$} & \multicolumn{4}{|c|}{ Mild cognitive impairment (MCI) } \\
\hline & & & & & $\begin{array}{l}\text { MCI } \\
\text { definition }\end{array}$ & $\begin{array}{l}\text { Total } \\
\text { sample } \\
\text { size }\end{array}$ & Cases & $\begin{array}{l}\text { Prevalence \% } \\
(95 \% \text { CI) }\end{array}$ \\
\hline Saha, 2010[92] & India & LMIC & $\geq 50$ & $\begin{array}{l}\text { Non-demented women, without } \\
\text { history of neurological disorders, } \\
\text { from a village of Singur block of } \\
\text { Hoogly district, Kolkata }\end{array}$ & $\begin{array}{l}\text { Cognitive } \\
\text { impairment }\end{array}$ & 179 & 76 & 42.4 \\
\hline Ruan, 2019[87] & China & UMIC & $\geq 60$ & $\begin{array}{l}\text { Residents from } 20 \text { communities } \\
\text { in the Zhoujiaqiao Primary } \\
\text { Health Service Area in } \\
\text { Changning district, Shanghai, }\end{array}$ & MCI & 5328 & 500 & 9.67 \\
\hline Inocian, 2016[69] & Philippines & LMIC & $\geq 65$ & $\begin{array}{l}\text { Elderly, with no diagnosed } \\
\text { mental health conditions, from } \\
\text { Cebu City }\end{array}$ & All MCI & 120 & 76 & 63.3 \\
\hline \multicolumn{9}{|c|}{ DSM-IV CRITERIA [104] (n=8 studies) } \\
\hline $\mathrm{Hu}, 2012[96]$ & China & UMIC & $\geq 55$ & $\begin{array}{l}\text { Non-demented residents of Nei } \\
\text { Monggol }\end{array}$ & MCI & 9266 & 1782 & 19.48 (18.43-19.99) \\
\hline Guo, 2013[72] & China & UMIC & $\geq 60$ & $\begin{array}{l}\text { Non-demented residents of six } \\
\text { towns of rural area of Hunan }\end{array}$ & aMCI & 1367 & 139 & $10.17(8.57-11.69)$ \\
\hline Zhang, 2015[77] & China & UMIC & $\geq 60$ & Non-demented residents of Taian & MCI & 1971 & 651 & 33.03 \\
\hline $\begin{array}{l}\text { Zhang and Zeng, } \\
2014[78]\end{array}$ & China & UMIC & $\geq 60$ & $\begin{array}{l}\text { Non-demented residents of } \\
\text { Changsha }\end{array}$ & aMCI & 1764 & 229 & $16.27(11.41-14.47)$ \\
\hline Zhou, 2009[82] & China & UMIC & $\geq 60$ & $\begin{array}{l}\text { Non-demented residents of } \\
\text { Xinjiang }\end{array}$ & aMCI & 2986 & 205 & $10.21(5.96-7.73)$ \\
\hline Zhou, 2011[81] & China & UMIC & $\geq 60$ & $\begin{array}{l}\text { Non-demented residents of } \\
\text { Ningbo }\end{array}$ & aMCI & 1227 & 107 & $10.68(7.14-10.22)$ \\
\hline Zhu, 2009[83] & China & UMIC & $\geq 60$ & $\begin{array}{l}\text { Non-demented residents of } \\
\text { Wulumuqi }\end{array}$ & aMCI & 1511 & 148 & $9.79(8.3-11.22)$ \\
\hline Xiong, 2013[90] & China & UMIC & $\geq 65$ & $\begin{array}{l}\text { Non-demented residents of } \\
\text { Tianjin }\end{array}$ & $\mathrm{aMCI}$ & 2798 & 339 & $11.38(10.91-13.26)$ \\
\hline
\end{tabular}

\section{Notes}

* Weighted prevalence for age using the World Health Organization world population estimates 2015. ${ }^{\dagger}$ Weighted prevalence for age, gender, and education level. ${ }^{\ddagger}$ Weighted prevalence calculated using reciprocal probability weighting based on the Sixth Nationwide Population Census in China, 2010. ${ }^{\S}$ Participants with 'all MCI' could be categorized in more than one MCI subtype. " Weighted prevalence using the direct standardization method adjusted by age and sex to the total Chinese population (according to the census conducted in 2005). "Weighted prevalence for stratification and age according to the WHO standard population. ${ }^{* *}$ Weighted prevalence according to the population structure as reported by the United Nations Statistical Division. " Weighted prevalence to account for selection probabilities and controlling for age and sex. 肺 Weighted prevalence to represent the total Mexican population. ${ }^{\S \S}$ The study from Shi, 2013 and Zhang, 2014 used data from the same cohort study.

Key

95\% CI Confidence Interval

alzMCI MCI caused by prodromal Alzheimer's disease

aMCI Amnestic MCI

CAR Central African Republic

CIND Cognitive Impairment No Dementia

cvdMCI MCI resulting from cerebrovascular disease

DR Dominican Republic

LIC Low Income Country

LMIC Lower Middle Income Country

MCI Mild Cognitive Impairment

MCI-A Mild Cognitive Impairment with significant memory impairment

MCI-MD Multi Domain MCI

MCI-O non memory / nonvascular related types of mild cognitive impairment

MCI-SD Single Domain MCI

MCI-VD significant executive function impairment and relationship with cerebral vascular disease naMCI Non-Amnestic MCI

NIA-AA National Institute on Aging and Alzheimer's Association

otherMCI MCI caused by other diseases

ROC Republic of Congo

UMIC Upper Middle Income Country

vrfMCI MCI with vascular risk factors 


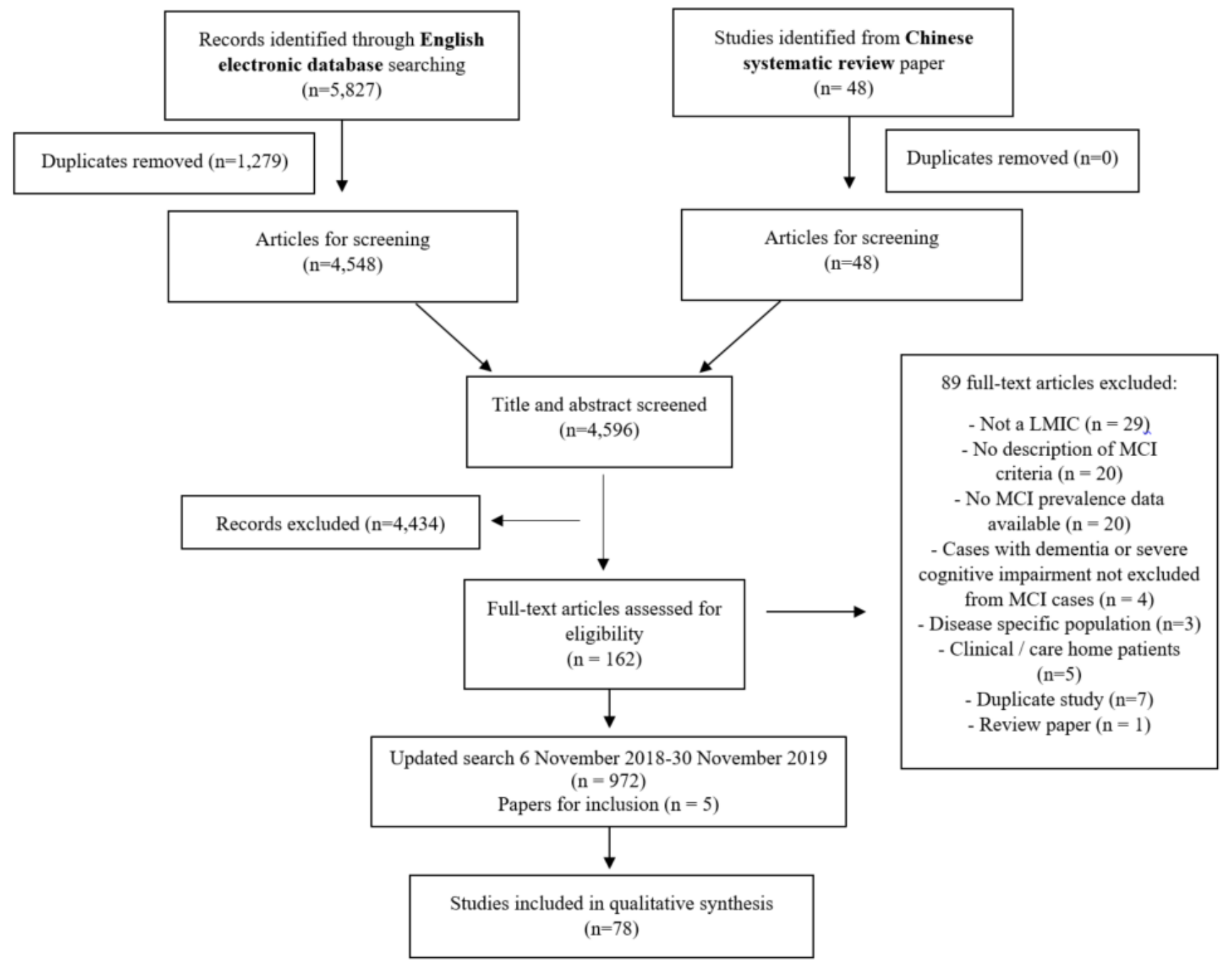

Figure 1 Study selection 


\section{$\mathrm{aMCl}$}

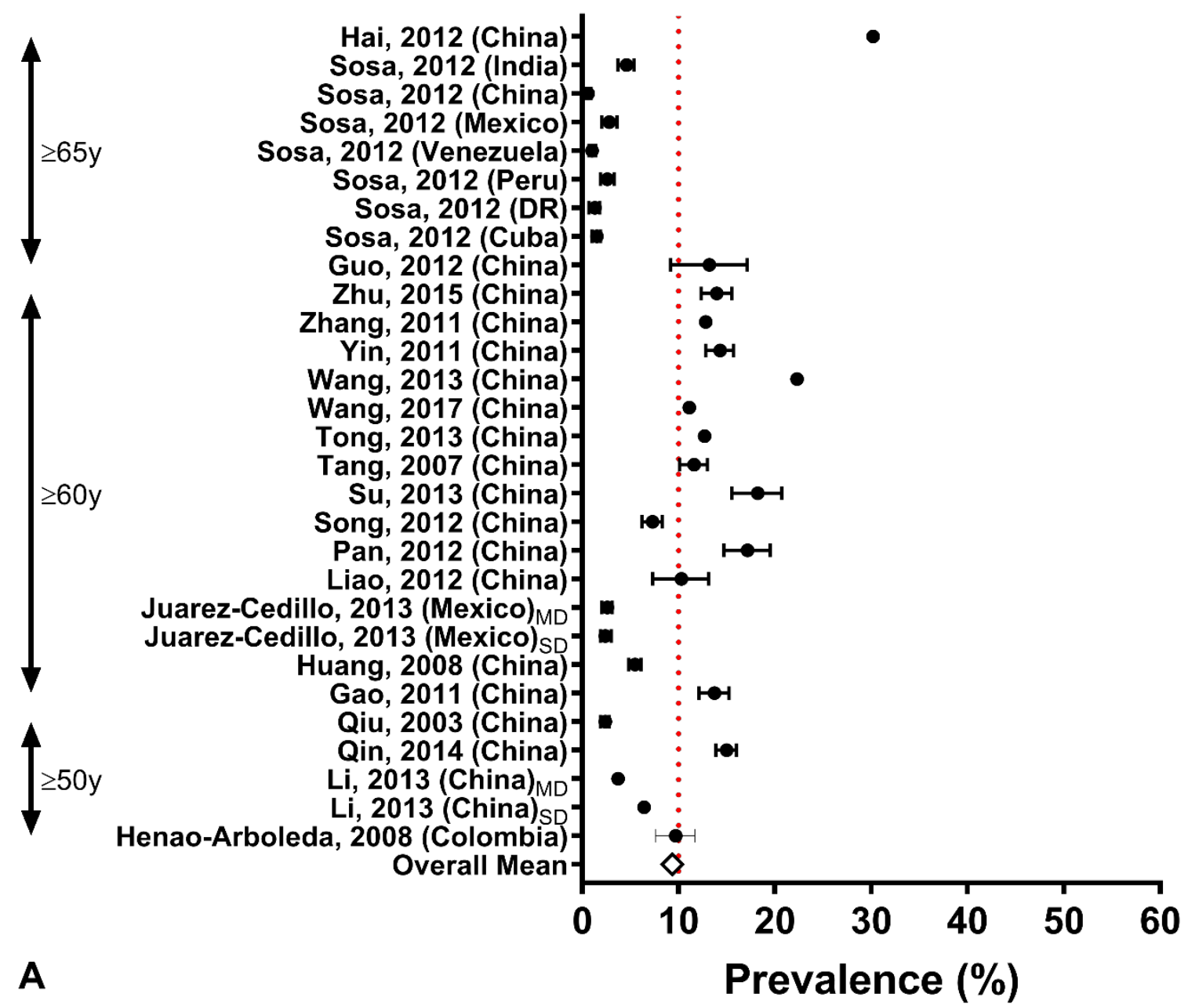

Figure 2A Forest plot of MCI prevalence from studies using Petersen’s criteria for Amnestic MCI (ordered by age). Note: red dotted line indicates $10 \%$ prevalence. Key 95\% CI 95\% Confidence Interval; aMCI Amnesic Mild Cognitive Impairment; DR Dominican Republic 


\section{All $\mathrm{MCl}$}

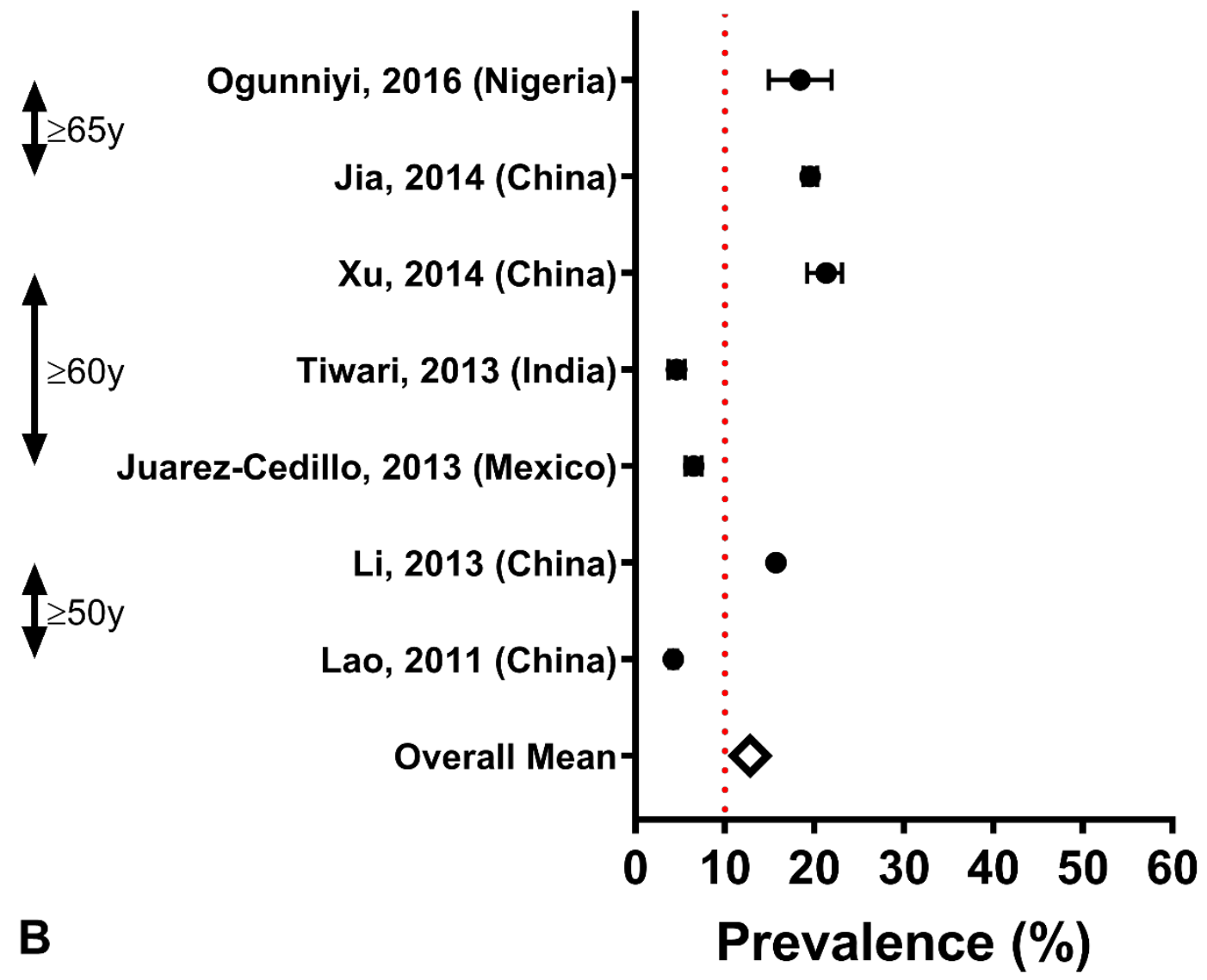

Figure 2B Forest plot of MCI prevalence from studies using Petersen’s criteria for All MCI (ordered by age). Note: red dotted line indicates $10 \%$ prevalence. Key 95\% CI 95\% Confidence Interval; MCI Mild Cognitive Impairment; 


\section{IWG All MCI}

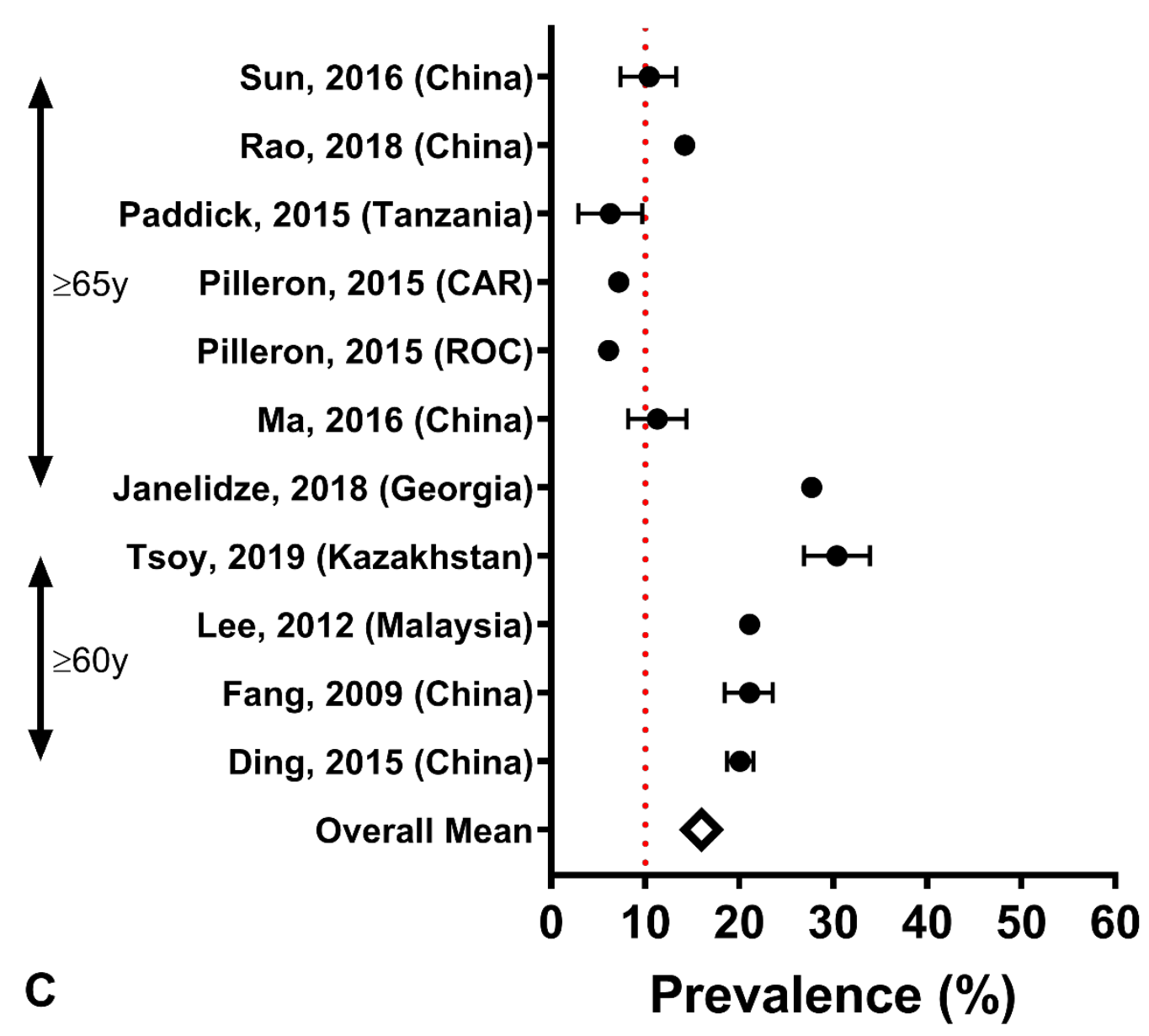

Figure 2C Forest plot of MCI prevalence from studies using the International Working Group criteria (ordered by age). Note: red dotted line indicates 10\% prevalence. Key 95\%CI 95\% Confidence Interval; IWG International Working Group; CAR Central African Republic; ROC Republic of Congo 


\section{CIND}

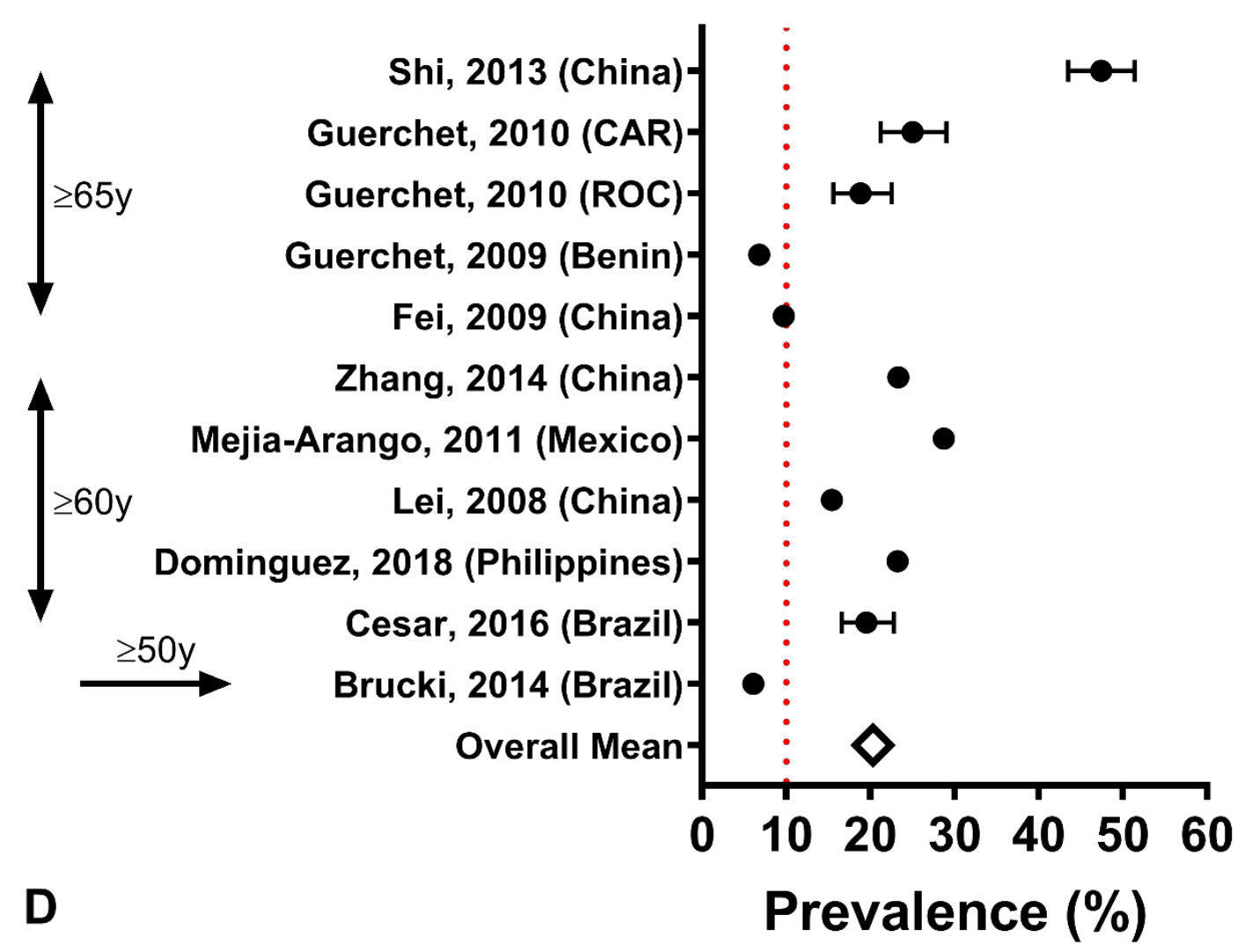

Figure 2D Forest plot of MCI prevalence from studies using definition of Cognitive Impairment No Dementia criteria (ordered by age). Note: red dotted line indicates 10\% prevalence. Key 95\%CI 95\% Confidence Interval; CAR Central African Republic; ROC Republic of Congo; CIND Cognitive Impairment No Dementia. 


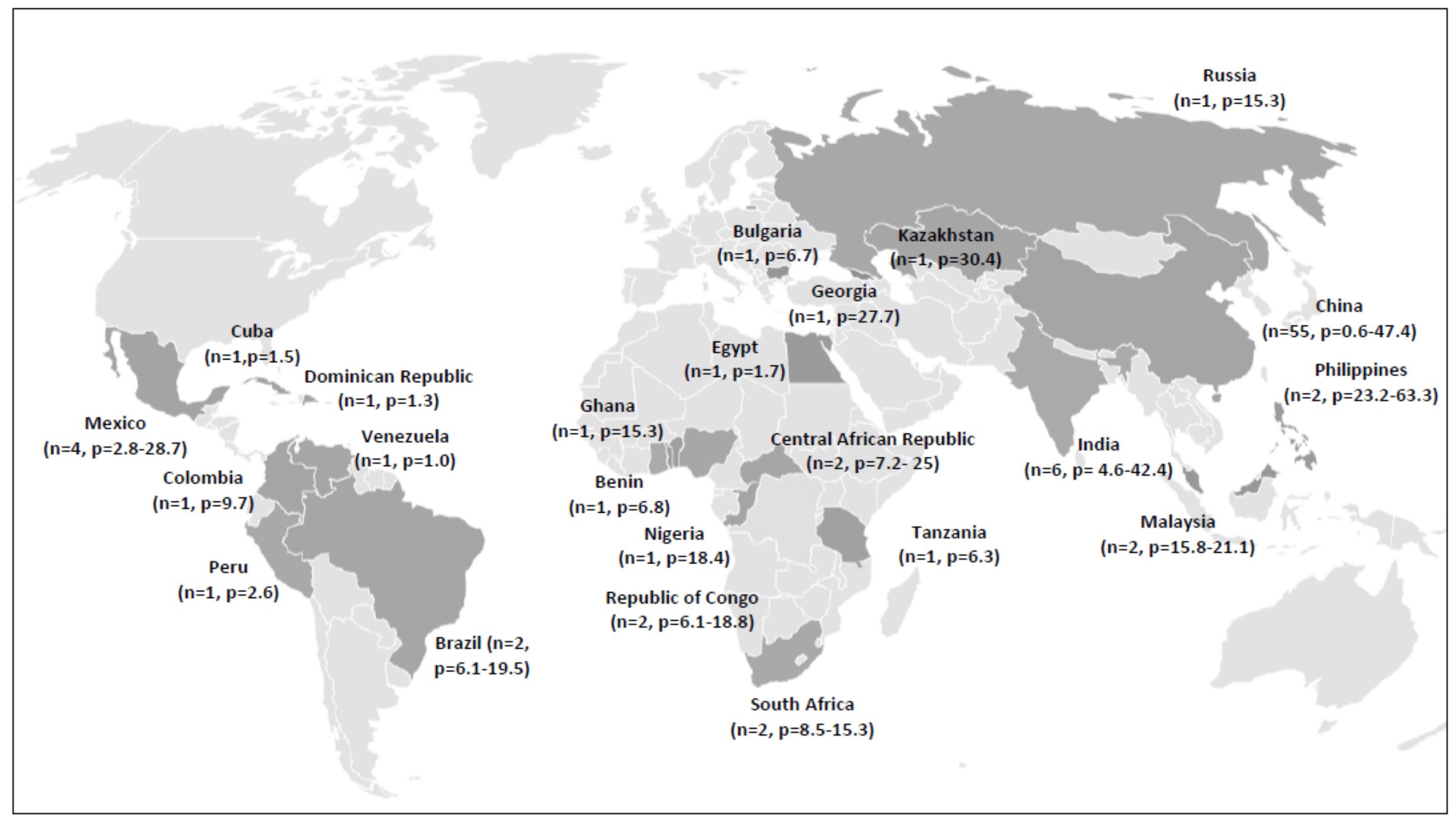

Figure 3 World Map showing each study site, number of studies in each site (n) and the reported MCI prevalence estimate(s) 